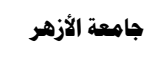

هجلة كلية الافات والترجمة

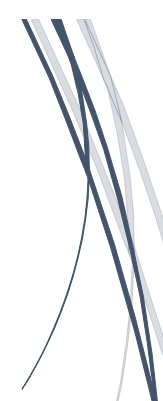

ضروب علم التعمية في الأشعار العثمانية المنقوشـة المثانية

على واجهات أسبلة القآهرة في العهد العثئمانية العبدانية

(1049هـ / 1639 م : 1286هـ / 1869م)

$$
\text { سارة طارق النادي }
$$




\section{ضروب علم التعمية في الأشعار العثمانية المنقوشة \\ على واجهات أسبلة القاهرة في العهد العثماني \\ (1049هـ / 1639م : 1286هـ /}

سارة طارق النادي

قسم اللغات الثرقية وآدابها، فرع اللغة التركية وآدابها، كلية الآداب جامعة عين شمس، القاهرة، مصر . البريد الإلكتروني: sara.tarek.elnadi@gmail.com

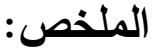

تستعرض هذه الدراسة ضروب علم التعدية التي وُظِّت في فن التأريخ العثماني، فقد نَظِمَ الثعراء العثمانيون تواريخهم بأنواعٍ مختلفة منل التاريخ التام، والتاريخ بالتعمية، والتاريخ الدُهمل، وغيرها من الأنواع الأخرى والتي تعتمد في نظمِهِا على استخدام حساب الجُمَّل والذى يُعد ضربًا من بن ضروب علم التعمية، وتقوم الدراسة بتدقيق الأنواع التي نُظَِِ بها في الأشعار المُدونة باللغة

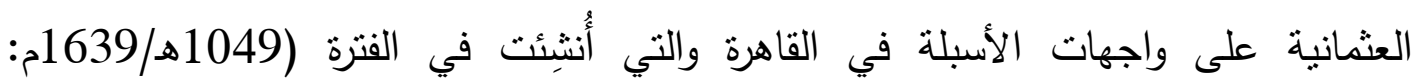
1286هـ/1869م)، وذللك باستخدام المنهج التاريخي والمنهج الاستدلالي. الكلمات المفتاحية: أسبلة، الثعراء العثمانيون، حساب الجُمَّل، علم التعمية، فن التأريخ

\section{Types of The Cryptography in The Ottoman Poems Inscribed on Facades of Sabils in Cairo in The Ottoman Period (1049 AH /1639 AD: 1286 AH /1869 AD)}

Sarah Tariq Alnadi

Department of Oriental Languages and Literature, Turkish Language and Literature Branch, Faculty of Arts, Ain Shams University, Cairo, Egypt.

Email: sara.tarek.elnadi@gmail.com

\section{Abstract:}

This study reviews the forms of Cryptography that have been used in the Ottoman Chronogram. The Ottoman poets composed their dates in various forms such as complete chronogram, chronogram with encryption, neglected chronogram and other forms that depend on using the Abjad numbers, which is a form of cryptography. The study examines the types that were composed in the poems written in the Ottoman language on the facades of Sabils in Cairo, which were established in the period (1049 AH /1639 AD: 1286 AH /1869 AD) by using the historical and deductive approaches. Keywords: Abjad numbers, Chronogram, Cryptography, Ottoman poets, Sabils 
هذه دراســة عن ضــروب علم التعمية التى وُظِّفت فى فن التأريخ العثمانى فى الأثــعار العثمانية التى ازدانت بها واجهات الأسـبلة فى العهد العثمانى فى الفترة (1639 - 1869م)، وتتكون الدراسة من مقدمة ومبحتان وخاتمة. تتناول المقدمة موضوع الدراسة، وأهمية طرح هذا الموضوع، كما تتناول المنهج المنبع فى الدراسة، ثم صعوبات وشكاليات التى واجنها الدراسة كثم ذكر الدراسـات السـابقة. وتلى المقدمة المبحث الأول الذى يتتاول الحديث عن علم التعمية وصـــلتهـ بفن التأريخ، ثم المبحث الثانى والذى يتتاول أنواع فن التأريخ من خلال التطبيق المباثر على النصوص الثعرية موضوع الدراسـة. أما الخاتمة فتتضمن النتائج التى توصلت إليها الدراسة، ثم ثبت بالمصادر والمراجع التى تم الاستعانة بها فى كتابة الدراسة.

\section{المقدمة:}

تستعرض هذه الدراسة ضروب علم التعمية التى وُظِّفت فى فن التأريخ العثمانى وذلك من خلال الأشعار العثمانية التى ازدانت بها واجهات الأسبلة فى العهد العثمانى فى الفترة (1639 - 1869م )، وهذا الفن اعتمد على حساب أبجد أو حساب الجُمَّل والذى يُعد ضربًا من ضروب علم التعمية، حيث تُحوَّل فيه الأرقام إلى حروف تُجمع قيمتها للحصول على الرقم المراد تأريخه. وقد تأثز الأدب بضروب علم التعمية بصفة عامة؛ حتى أصبح من المستحسن أن يلم الأديب بطرف منها، وانتشر هذا العلم وضروبه بين الأدباء؛ حيث رأوا فى التعمية رياضةً ذهنية ومتعة يتبادلونها فيما بينهم. وقد اطلّع الأدباء العثمانيون على هذا العلم ووظفوا ضروبه فى تعمية تواريخهم بحساب الجُمّل، فقد أرخوا بأنواعٍ مختلفة للأحداثٍ والوقائع المهمة باستخدام هذه الضروب، والتى أدرجوها تحت أنواع فن التأريخ، والذى يُعد أحد ألوان البديع فى أدبهم، ولا بد أن يتطابق الوزن والقافية والمعنى فى البيت الذى يحمل التاريخ مع سنة التاريخ التى يُؤرخ لها. ويُعرف هذا الفن فى الأدب العربى بالتأربخ الثعرى أو التأربخ الحرفى. 
وأهمية هذه الدراسة تتمثل فى أهمية فن التأريخ فى حد ذاته، فهو من ناحية؛ يخدم مجال الدراسات التاريخية والأثرية، ومن ناحية أخرى؛ له أهمية فى الدراسات الأدبية. ففى المجال التاريخى والأثرى: يُعد مصدرًا مهمًا وموثوقًا به لتأريخ المنشآت المعماربة بصفة عامة إذا سُجل عليها نصوص تأسيسة تتضمن هذا الفن، ولا نغفل دور مصادر الكتب التاريخية ومؤرخيها فى تأريخ منشئة ماء إلا أنه لا يمكن الوثوق بها ثقة تامة، حيثُ وُجد بها معلومات مغلوطة بخصوص تواريخ الإنشاء لبعض الأسبلة، ومن هنا جاءت أهمية فن التأريخ فى إثبات صحة ما وُرد فى هذه المصادر التاريخية أو نفيه. وأما من الناحية الأدبية فهذا الفن الأدبى الذى يندرج ضمن ألوان البديع فى كتب البلاغة العثمانية؛ يكثف لنا إبداع الثعراء العثمانيين الذين أرخوا به فى لهى النصوص موضوع الدراسة، فقد جاءت نواريخهم فى الأدب الديوانى بأنواع مختلفة وعلى نهج مبتكر وتشمل الدراسة تأريخ ثمانية عشر سبيلًا مما ازدانت واجهاتهم باللغة العثمانية، وهذه الأسبلة قد حوت خمسة وعشرين نصًا يتضمن هذا الفن البديع، وقد جُمعت عن طريق الدراسة الميدانية، والتى من خلالها حُصرت هذه النصوص وصُوِّرت ورُتبتت ترتبيًا زمنيًا من القرن السابع عشر الميلادى وحتى القرن التاسع عشر الميلادى، ثم دراسة هذه النصوص بالاعتماد على المنهج التاريخى والمنهج الاستدلالى للتعريف بهذا الفن وبأنواعه، ثم التطبيق على النصوص موضوع الدراسة، وبهذه المنهجية قد صُحح تاريخان من تواريخ الإنشاء لسبيل إبراهيم أغا مستحفظان وسبيل محمد كتخدا، كما أُثبت أن الأنواع المختلفة لفن التأريخ الذى تفنن فيه الشعراء العثمانيون؛ ما هى إلا ضروب لعلم التعمية الذى يُنتسب للعرب ولادة ونشأة وتطورًا. وتظبيق ضـــروب علم التعمية على فن التأريخ الذى نُظٍ به فى الأثـــعار العثمانية التىى إزدانت بها الأسـبلة موضـوع الدراسـة؛ لم يسبق تتاوله من قبل فى أقسـام اللغة التركية، أو فى لـ كليات الآثار • وتتمنل صسعوبة هذه الدراسـة فى جمع المادة العلمية والتى اعتمدت على الدراسـة الميدانية لحصـر جميع الكتابات العثمانية على الأسـبلة فى القاهرة، كما تمثلت الصـعوبة فى 


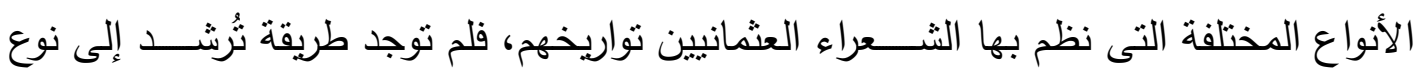
التاريخ المستخدم لتأريخ تأسيس المنشـأة باسـتثناء نوعين من التواريخ، الأول: التاريخ بحسـاب الحروف المنطوقة أو كما يُطلق عليه "التاريخ المُعجم" حيث يذكر الثـاعر فى نظم هذا التاريخ كلمة تدل على استخدامه لهذا النوع مثل كلمة (منقوط، أو جوهر ، أو مجوهر)، والثانى : التاريخ التام ويذكر الثــاعر فى نظم هذا التاريخ كلمة ( تام ) فى البيت الذى يحمل التاريخ. أما غير ذلك من أنواع النواريخ الأخرى، فيعتمد طريقة معرفتها على الاستنباط ومُحاولة تطبيق كل نوع من أنواع التواريخ على البيت أو الثطر الذى يتضـمن التاريخ حتى نحصل على سنة التاريخ التى توافق سنة الإنشاء التى نقتش بالأرقام فى نهاية البيت الذى يحمل التاريخ. المبحث الأول: علم التعمبة وصلته بفن التأريخ: يستعرض هذا المبحث التعريف بعلم التعمية وبفن التأريخ لغة واصطلاحًا، وذكر الصلة بينهما، ثم الكيفية التى نظم بها الثعراء التاريخ وذللك على النحو التالى: أولًا: علم التعمية وصلته بفن التأريخ: إن التعميةَ فَى اللغةة: من ( عَمَىَ )، وهو ذهاب البصر ، والتعمية هى أن تُعَمَِّ على الإنسان شيئًا فتُلبّسه عليه تلبيسًا، وهى الإخفاء والتلبيس، وعميت معنى البيت تعمية(1)، أما التعمية اصطلاحًا: فهى مصطلح كناية عن تحويل نص واضحح إلى نصٍ غير مفهوم باستعمال طريقة محدة، يستطيع من يعرفها أن يعود ويفهم النص، واستخراجها عكس ذللك، حيث يجرى فيه تحويل النص المعمى إلى نص واضح. ولقد درج فى أيامنا هذا استعمال كلمة ( التتفير) بدلًا من كلمة التعمية. واستعمال (حل الثفرة / كسر الثفرة ) بدلاً من استخراج المعىى. وعلم التعمية واستخراج المعمى هو علم عربى المولد، يعود الفضل إلى العرب فى ابتكاره، ووضع أسسه، وإرساء قواعده، وتطويره إلى أن بلغ مرحلة ناضجة، وغدا ما وضعوه فيه مرجعًا قَبَسَ منه المشتغلون بالتعمية. ويحظى هذا العلم بأهمية بالغة فى العالم الغربى، إذ تتوعت تطبيقاته العملية وشملت مجالات متعددة منها: المجالات الدبلوماسية، والعسكرية، والأمنية، والتجارية، 
والاقتصادية. وقد انتشر هذا العلم فى طبقات شتى من المجتمع؛ فنهم الجاد الذى يريد لهذا العلم أن يؤدى رسالته الثريفة فى خدمة الدولة، وصيانة حدودها والحفاظ عليها،.... ومنهم من يرى فى التعمية رياضة ذهنية ومتعة يتبادلها المتأدبون، ومما يُشير إلى الآفاق التى طوّف فيها علم التعمية؛ ما نصادفه فى كتب المحاضرات والأدب من مقتطفات تطول أو تقصر عن التعمية التى يُحسن بالأديب أن يُلمَّ بطرف منها. ومن ضروبٍ علم التعمية: - تعدية المعانى بالتورية، وهى لا تتبع قواعد محددة، بل تعتمد على فطنة المتراسلين وخبرتهم وثقافتهم، وهى تُشتخدم فى الأعمال البديعية أو الأدبية.

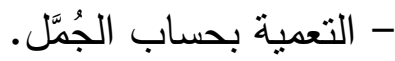
- التعمية بالكلمة المحتملة، وهى من الاستدلالات القوية لمعرفة استخراج المُعمى. - التعمية بالإخفاء، وتكون باستعمال حروف المُهمل والمستعمل. - التعمية باستعمال المضاعف من الحروف أو من ثنائيات الحروف. - التعمية بوصل المتفرق من الحروف أو تفرقة المتصل من الحروف. - التعمية بالقلب، وتكون بتغير مواضع الحروف. - التعمية بالإعاضة أو التبديل، أى تبديل الحروف بحروف أخرى. - التعمية بزيادة حروف أو حذف حروف.

- التعمية بتركيب الحروف على رُقعة الثطرنج، وهذه الطريقة تقوم على الإعاضة البسيطة(2). مما سبق يُجدر الإشارة إلى نقطةٍ مُهمة ألا وهى أن حساب الجُمَّل نفسه ماهو إلا ضربّ من ضـــروبٍ علم التعمية، وهذه الطريقة فى التعدية المبذية على تحويل الحروف إلى رموز رقمية، ثم مُعالجة هذه الأرقام بإجراء عمليات حسابية عليها، ثم العودة إلى الحروف من جديد، تُعدُّ - هذه الطريقة - المد الأساسى المطبق فى عمليات التعمية(3). وما يُلفت الانتباه؛ أن هذه الضــروب المذكورة أعلاه كانت الروافد الأســاسـية التى اســـمد منها الأدب العربى والأدب الديوانى أنواعًا مختلفة لتأريخ الوقائع والأحداث المهمة وذلك بتعمية التاريخ بحســاب الجُمّل، 
فيُلاحظ أن الثــــعراء ناظمى التواريخ فى كلا الأدبين قد نظموا تواريخهم بأحد ضـــروب علم التعمية، وقد قتّموا أنواع نواريخهم بالاعتماد على هذه الضـروب. وما يلى عرض لفن لفت التأريخ

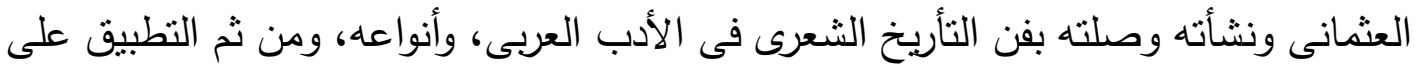

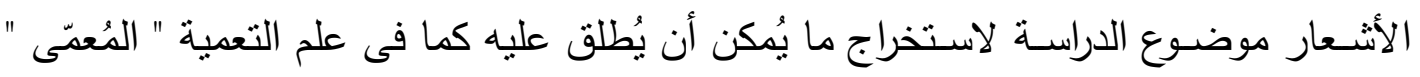

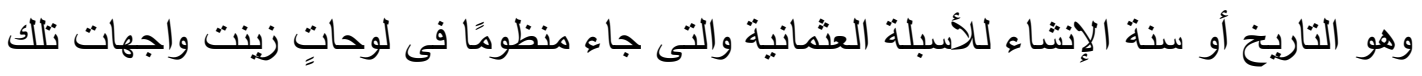
الأسبلة فى الفترة موضوع الدراسة.

\section{ثانيًا: فن التأريخ فى الأدب الديوانى (تعريفه، نثأته وتطوره) :}

tarih ) يُطلق على فن التأريخ باللغة العثمانية (صنعت تاريخ) (4) وباللغة النركية الجديثة (düşürme, tarih söyleme

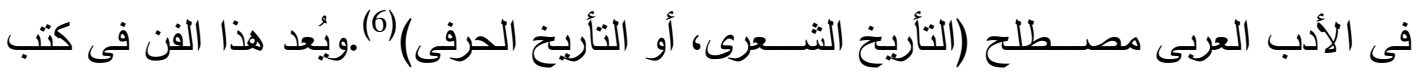
البلاغة العثمانية من فنون البديع الذي هو أحد فروع علوم البلاغة العربية الثثلاثة: (البيان، والمعاني، والبديع). والمقصود بالتأريخ فى اللغة: تعريف الوقت ، والنتَّريخُ منله. أَرَخْ الكتابَ ليوم كذا: أى وَقَتَّه (7).

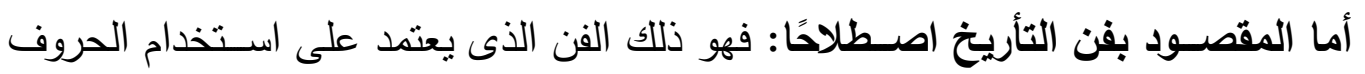

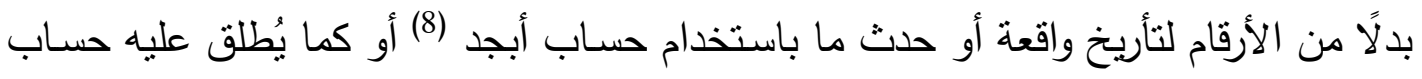

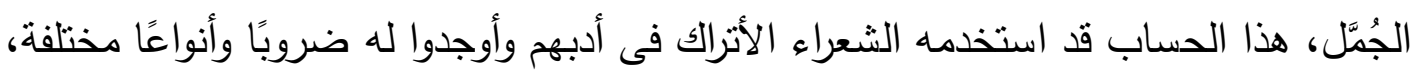

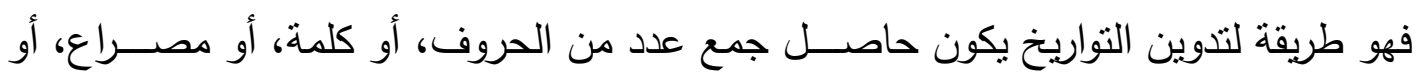

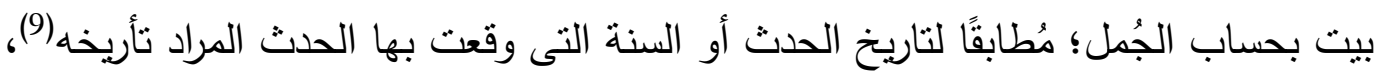
حيث إن لكل حرف فى هذا الحساب قيمة عددية على النحو النالى (10): 


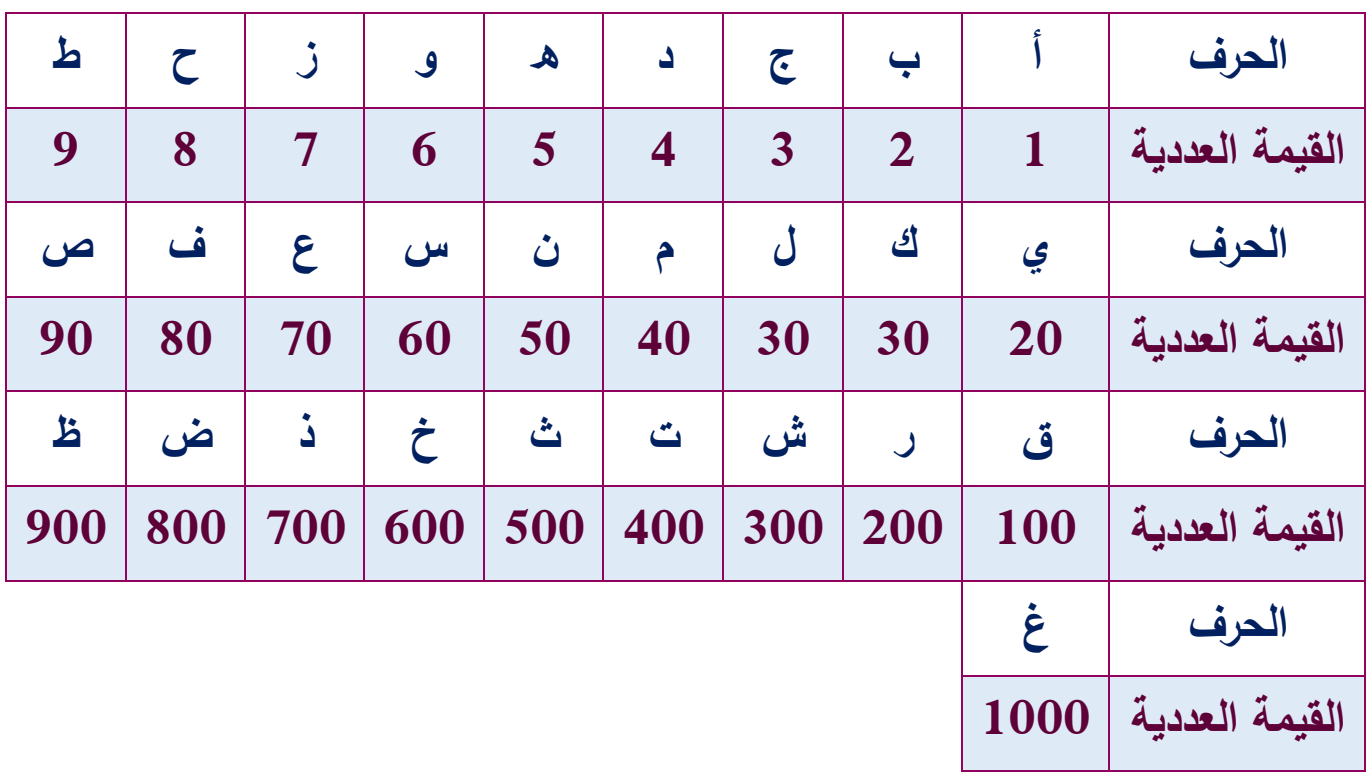

وباستخدام هذا الحساب أصبح التأريخ فنًا فى الأدب التركى، فقد وُظِّف لتأريخ العديد من الأحداث منل: (تولى السلاطين الحكم، الولادة، الزواج، الحرب، السلام، الموت، ...إخخ)، كما استخدم أيضًا فى مجال العمارة لتأريخ المبانى الأثرية، مثل: (القصور، المساجد، الأسبلة، ...إخخ) واستخدم لتأريخ الحوادث الطبيعية، منّ: (الحرائق، الزلازل، الأوبئة،...إلخ). ولذلك أُطلق على ناظم التاريخ لقب الثاعر المؤرخ، نظرًا لتسجيله الأحداث والوقائع شعرًا حيث تكون هذه التواريخ التى أُسقطت بحساب الجُمَّل لتوثيق هذه الأحداث المصدر الرئيس والوحيد لها فى له بعض الحالات(11)، ويجب على الثاعر أن يلتزم بتطابق الوزن والقافية والمعنى مع رقم التاريخ المراد تأريخه(12)، فإذا التزم الثاعر فى البيت الذى بحمل التاريخ بالوزن والقافية وفى الوقت نفسه توافقت الدلالة مع التاريخ أى: جاء بيت التاريخ واضـح المعنى وذا علاقة بموضوع الحدث المؤرخ له؛ يكون التأريخ المنظوم فى هذه الحالة مستحسنًا ومقبولًا (13. وقد اختلف مؤرخو الأدب التركى فى الفترة الزمنية التى بدأ فيها استعمال هذا الفن فى الأدب التركى؛ ففى حين أن طاهر المولوى يذكُر بأنها غير معلومة(14)؛ يقول أحمد جودت إن فن التأريخ فى بادىء الأمر لم يكن موجودًا فى الأدب التركى، ولكن بعد ذلك اعتاد الأدباء على بهى استخدامه فى تأريخ واقعة ما بكلمة، أو بعبارة ، ففى حين أن هذا الفن كان مُستخدمًا فى البداية 
فى النصوص النثرية؛ إلا أنه قد وُجد أول تأريخ منظوم فى سنة (850 هـ - 1446م ) حين أرخ (خضر بك) لمسجد أقامه السلطان محمد خان الثانى (محدد الفاتح )، فنظم مصراعًا تأريخًا

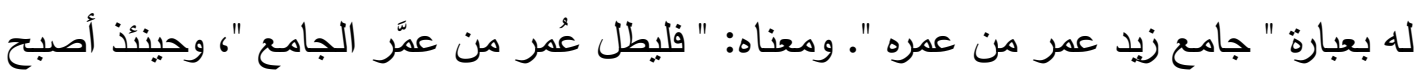

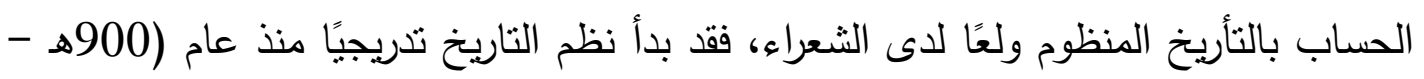

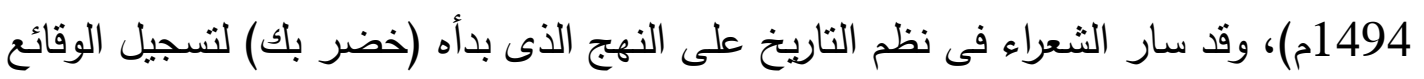

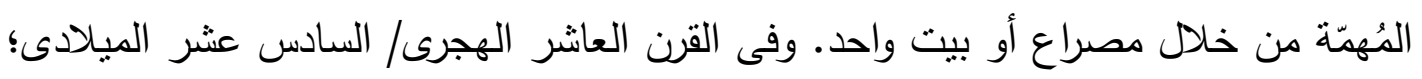

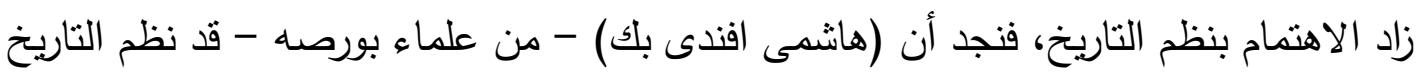

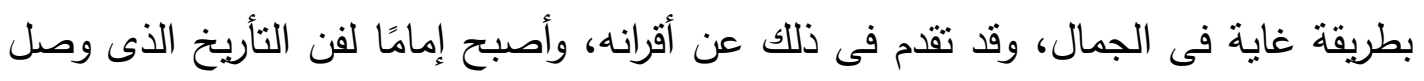

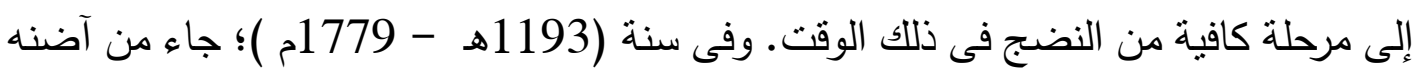

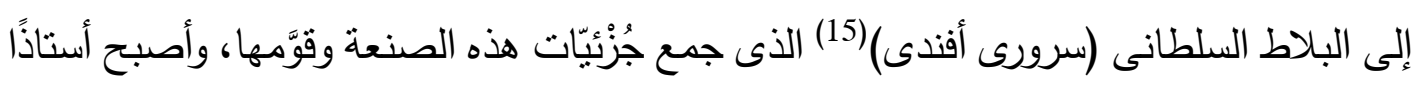

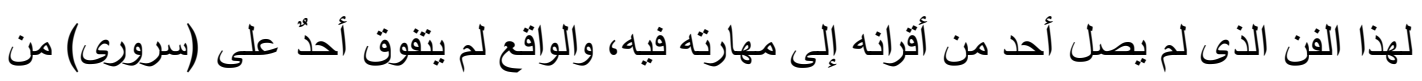
أسلافه أو من أخلافه فى هذا الفن، فقد سجل الوقائع المهمة النى حدثت حتى فى الأزمنة السابقة عليه بالثاريخ المنظوم بصورة أفضل وأجمل (16). أما الكيفية التى نظم بها الثعراء التاريخ، فنجد أنه قد كُتب بطرُقِ متعددة؛ منها المباشر

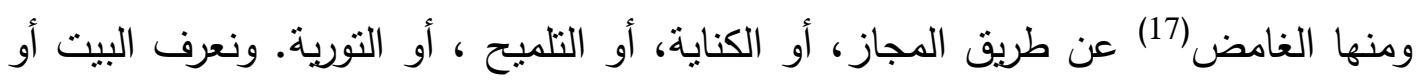

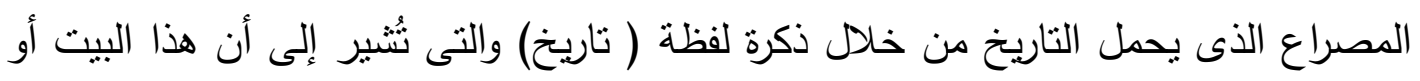
المصراع يحمل التاريخ المنظوم. وقبل سرد الأنواع الدختلفة التى نظم بها الثعراء الأثراكل تواريخه؛ لابد من ذكر بعض القواعد النى يجب اتباعها عند حساب القيمة العددية للتاريخ

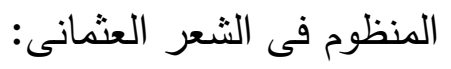
• يكون حساب النواريخ بالإعتبار الخطى وليس الإعتبار اللفظى، فمثلًا الياء فى كلمة

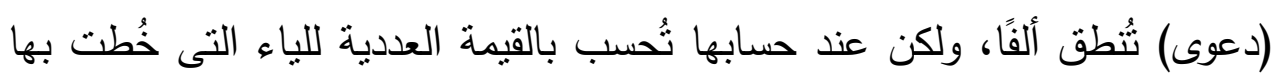
وليس الألف التى تُطق بها(18). 
• الهزة ( ء) منل الألف ( 1 )، تُطابق الألف فى القيمة العددية وهى (1)(19). • إن الكلمات منل (نساء) قد ثُرك استخدام الهمزة سواء لفظيًا أو خطيًا فى اللغة العثمانية، فأصبحت تُكتب (نسا) وتُنطق بدون همزة، ولكن؛ إذا جاءت بوصفها اسمًا موصوفًا أو مُضافًا؛ فإن الهمزة تُعاد لها مرة أخرى منلك: (نساء حسان)(20). إن الحروف الخاصة باللغة الفارسية والتركية وهى: ( ب ، تج ، ز ، ك )، لها القيمة العددية نفسها للحروف المتجانسة لها فى العربية وهى: ( ب ، ج ، ز ، ك ) (21). وفى كل هذه الدراسة قد النُزم بكتابة الأبيات التى تحمل التواريخ كما خُطَّت تمامًا فى اللوحات الكتابية.

\section{المبحث الثانى: أنواع فن التأريخ:}

تعددت الأنواع التى نُظم بها التاريخ، وما يلى عرض لأنواع التاريخ التى نظم بها شعراء الديوان التواريخ التى أرخوا بها لسنوات الإنشاء للأسبلة العثمانية فى الفترة (1639 - 1869م)، ونظرًا لكثرة الشواهد وتعددها؛ سيكون التطبيق مقصورًا على ما اختلف من الشواهد فقط. 1. التاربخ التام (تام تاربنخ):

يُطلق عليه أيضًا التاريخ المستوفى أو التاريخ المطلق ( مستوفى / مُطلق تاريخ )، ذلك لكون حاصل جمع جميع حروف المصراع، أو البيت، أو الجملة؛ مطابقًا تمامًا لسنة تاريخ الواقعة، فنحصل على التاريخ بجمع الحروف بطريقة مباشرة، فإذا أراد الثناعر أن ينظم تاريخه دون تعمية؛ فهو يستخدم هذا النوع من التواريخ(22)، ويُعد هذا التاريخ أثند قوة وقبولاً بين أنواع التواريخ المتعددة. ولذلك نجد هذا النوع قد نُظم به أغلب النصوص التى ازدانت بها واجهات الأسبلة، حيث إن خمسة عشر نصًا من أصل أربعة وعشرين نصًا يحمل هذا التاريخ وذلك

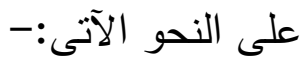


سبيل ابراهيم أغا مستحفظان:

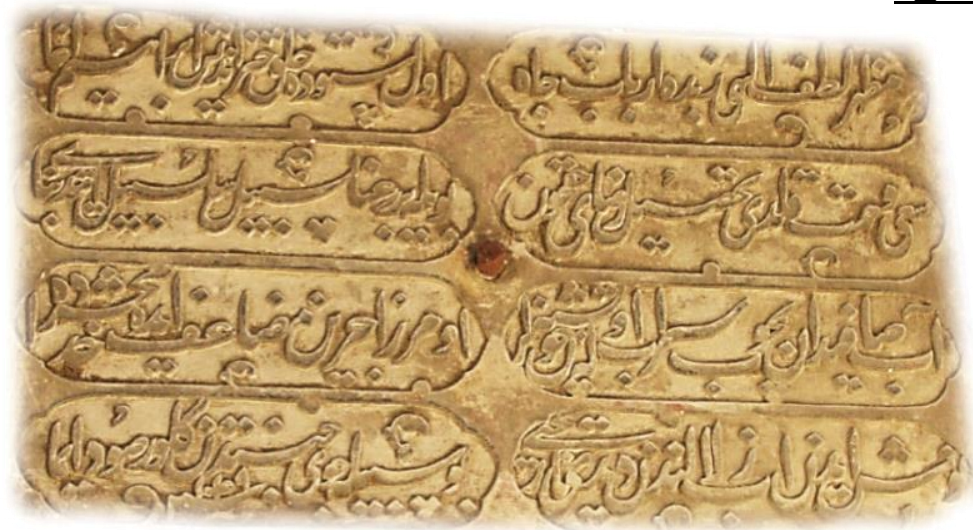

جاء البيت الأخير من هذا النص :

نوش ايدن اب زلالندن دياى تاريخنى ... بو سبيله جوى جنتن كلور صو دايما سنة $10+9$

فبعد كلمة " تاريخنى " هنا ؛ نقوم بجمع القيمة العددية لحروف المصراع التالى لها لنجد أنه يوافق سنة (10٪9هـ )، وقد كُنب الرقم (4) هنا بالأرقام الفارسية، وذلك كما يلى:

\begin{tabular}{|c|c|c|c|c|c|c|c|}
\hline دايما & صو & كلور & جنتدن & جوي & سبيله & يو & الكلمة \\
\hline 56 & 96 & 256 & 507 & 19 & 107 & 8 & قيمتها العددية \\
\hline \multicolumn{7}{|c|}{1049} & المجموع \\
\hline
\end{tabular}

ويجب هنا الإثتارة إلى أهمية فن التأريخ من ناحية؛ وأهمية الكتابات الأثربة من ناحية

أخرى، فقد صُحح تاريخ إنثاء هذا السبيل الذى جاء تاريخه (1051هـ) على اللوحة التعريفية المثبتة على السبيل من قِبل المجلس الأعلى للآثار وذلك كما فى الصورة التالية. كما جاء تاريخ إنشاء هذا السبيل فى كتاب اوليا جلبى (1037هـ) وهو تاريخ غير دقيق(23). 

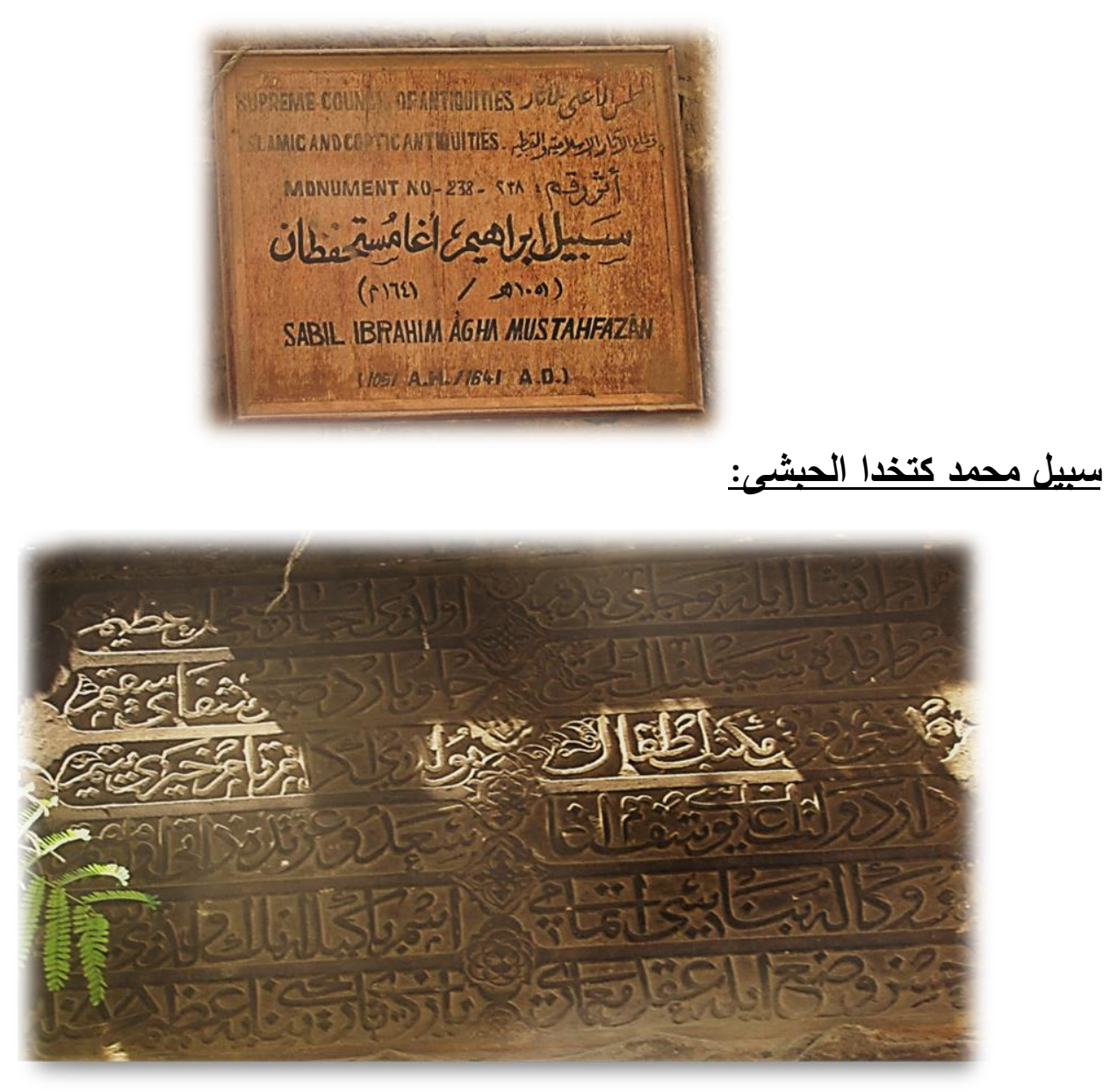

$$
\text { جاء البيت الأخير من هذا النص : }
$$

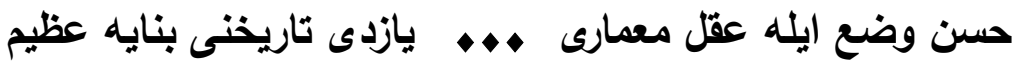

\section{سنة 1088}

فى هذا النص لم يأتِ التاريخ مصراعًا كاملًا ولكن جاء التاريخ فى تركيب (بنايه عظيم)، حيث جاءت بالتاريخ التام مطابقة لسنة (1088هـ ) على النحو التالى:

\begin{tabular}{|c|c|c|}
\hline عظيم & بنايه & الكلمة \\
\hline 1020 & 68 & قيمتها العددية \\
\hline \multicolumn{2}{|c|}{1088} & المجموع \\
\hline
\end{tabular}


سبيل وكتاب على أغا دار السعادة:

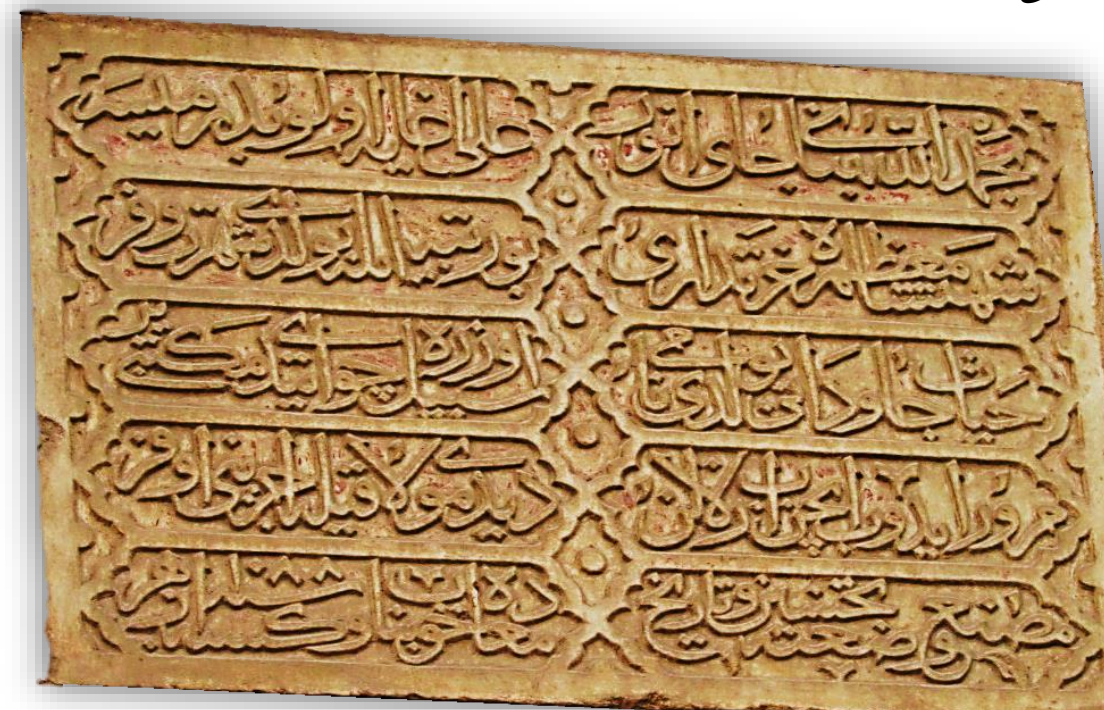

جاء البيت الأخير من هذا النص :

\section{مصنع وصنعته تحسين وتاريخ .... معاده خوب بنا وكسبه ازهر}

\section{سنة 1088}

جاء المصراع بعد كلمة " تاريخ " منظومًا بالتاريخ التام إلا أنه إذا التزمنا بحساب

الحروف بهذا الرسم الخطى نجد أن قيمتها العددية تتقص رقم واحد، ونجد أن كلمة " بنا " قد

خُطت بدون الهمزة؛ فهى لا تُطق ولا ثُكتب فى اللغة العثمانية كما أوضحنا من قبل فى القواعد التى يجب اتباعها عند حساب القيمة العددية، " فإذا أعذنا الههزة والتى تساوى رقم (1)؛ نحصل على السنة التى توافق بها ناريخ إنشاء السبيل وهى سنة (1088هـ ) وذلك كما يلى:

\begin{tabular}{|c|c|c|c|c|c|}
\hline ازهز & وكسبه & بناء & خوب & معاده & الكثمة \\
\hline 350 & 93 & 54 & 608 & 120 & قيمتها (العددية \\
\hline \multicolumn{5}{|c|}{1088} & المجموع \\
\hline
\end{tabular}




\section{سبيل محمد على (العقادين):}

يحمل هذا السبيل ثلاثة نصوص، نص شعرى يعلو شبابيك السبيل، والنص الثانى يعلو

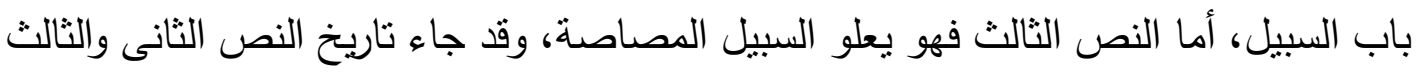
منظومًا بالتاريخ التام على النحو التالى: النص الذى يعلو باب السبيل:

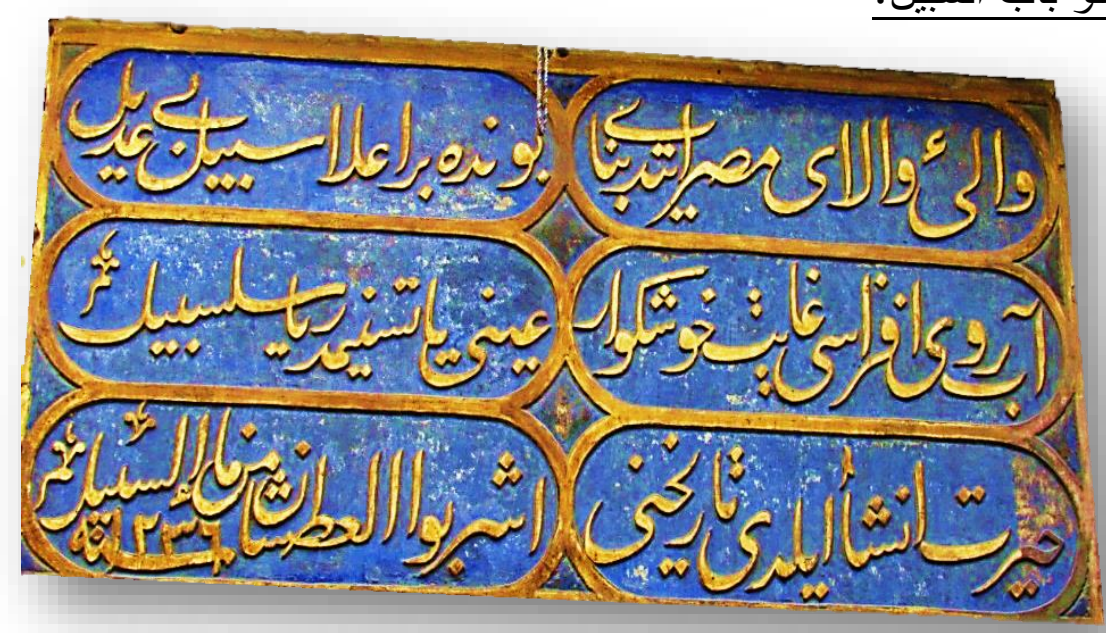

$$
\text { جاء البيت الأخير من هذا النص : }
$$

حيرث انثا ايلاى تاريخنى .... اشريوا العطشان من ماء السبيل

\section{سنة 1236}

جاء المصراع بعد كلمة " تاريخنى " منظومًا بالتاريخ التام حيث إن القيمة العديدية

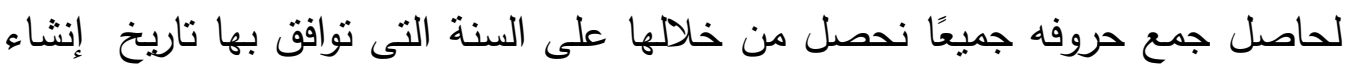
السبيل وهى سنة (1236هـ ) وذللك كما يلى:

\begin{tabular}{|c|c|c|c|c|c|}
\hline السبيل & ماء & من & العطثان & اثشربوا & الكلمة \\
\hline 133 & 42 & 90 & 461 & 510 & القيمة العددية \\
\hline \multicolumn{5}{|c|}{1236} & المجموع \\
\hline
\end{tabular}


النص الذى يعلو السبيل المصاصة:

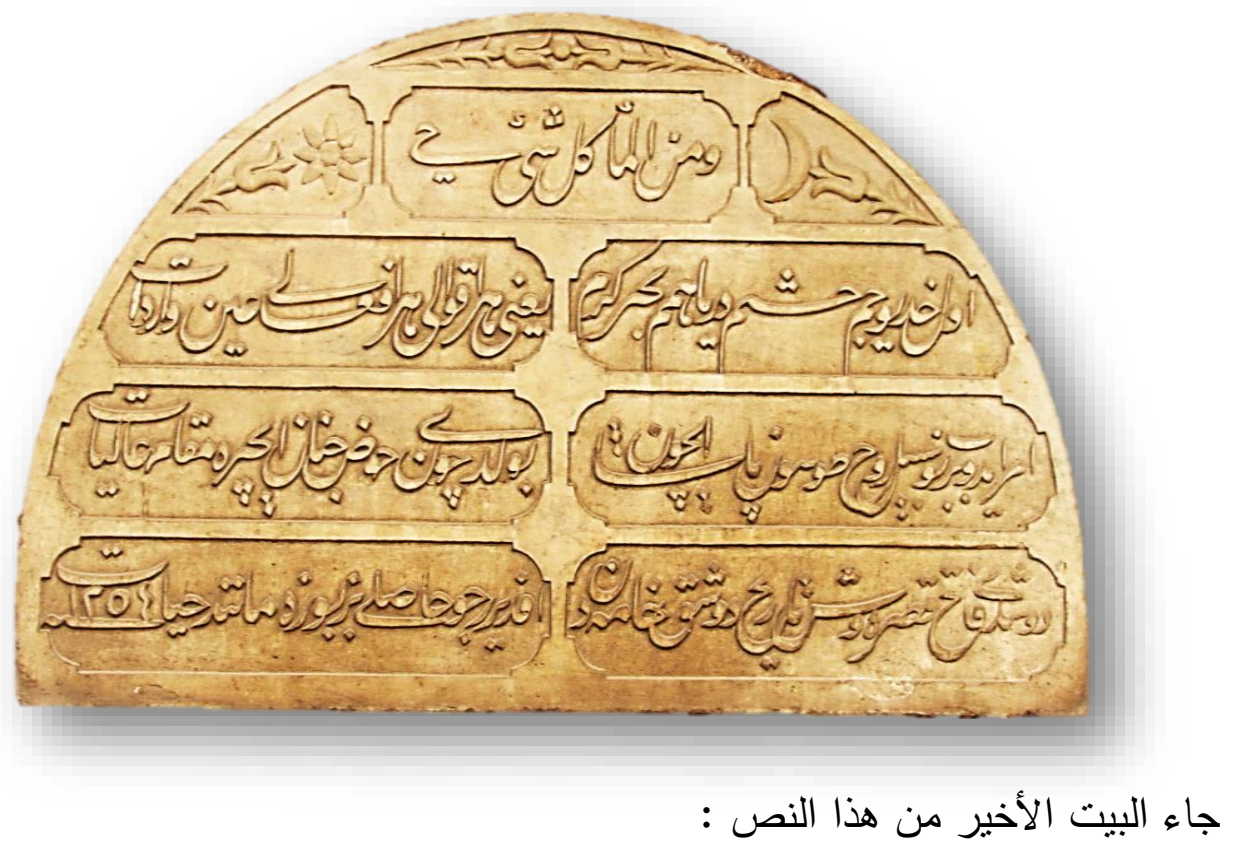

دوشدى فاتح قطره وش تاريخ دو شق خامه دن ... اقديرر جو حاصلى بزبوزه مانتد حيات

\section{سنة 1254}

جاء هذا التاريخ فى هذا النص بنوعين من التواريخ: الأول التاريخ التام وذلك إذا حسبنا جميع الحروف فى المصراع الأخير كما هى فنحصل على التاريخ الأصلى لإنشاء السبيل وهو (1236هـ)، ولكن الثناعر أبدع فى نظم تاريخه لتأريخ السبيل المصاصة الذى أنثىئ سنة (1254هـ) كما نُقش بنهاية النص، واستخدم نوعًا آخر من التواريخ؛ ألا وهو تاريخ التعمية - وسوف نذكر ذلك فى تاريخ التعمية - حيث إنه استخدم من ضروب علم التعمية ضرب التعمية بالإعاضة أو التبديل، أى تبديل الحروف بحروف أخرى، فأصل كلمة (افيرر) هنا ( اقديرر ) والتى تتوافق مع معنى البيت، ولكنه بدّل حرف القاف بحرف الفاء لكى نحصل على تاريخ إنشاء السبيل الأصلى وتاريخ إنثاء السبيل المصاصة الذى أُلحق بعمارة السبيل فى عام (1254هـ)، والواقع " فاتح "(24) ناظم هذا النص قد لمّح لنا بذلك فى المصراع الأول من هذا البيت والذى ترجمته: 
يا فاتح لقد وقع تاريخه من القلم كالقطرة فى شقين

والمحصلة اسال الصنبور الماء كالحياة

يتضح هنا من ذكر شقين؛ أنه أرخ تاريخين كما أسلفنا الذكر . والجدول التالى هو توضيح

لنوع التاريخ الأول وهو التاريخ التام وذلك كما يلى:

\begin{tabular}{|c|c|c|c|c|c|c|}
\hline هيات & ماتند & بزبوزه & حاصلى & جو & افدير & الاكمة \\
\hline 419 & 145 & 29 & 130 & 9 & 495 & |لقيمة العددية \\
\hline \multicolumn{6}{|c|}{1236} & المجموع \\
\hline
\end{tabular}

جاء التطبيق على هذه النصوص التى نُظم بها بالتاريخ التام، وهنالك نصوص أخرى نُظٍ تاريخها بالتاريخ التام وهى نص سبيل السلطان محمد الرابع (1077هـ)، نص سبيل آق سنقر الفارقانى (1080هـ)، نص سبيل إبراهيم جورباجى (1106هـ)، نصوص سبيل بشير أغا (1130هـ ، 1131هـ)، نص سبيل محمد على بالنحاسين (1244هـ)، نصوص سبيل والدة أحمد رفعت باشا (1281هـ ، 1282هـ)، نصوص سبيل أم عباس وكلاهما يوافق سنة $\cdot(1284)$

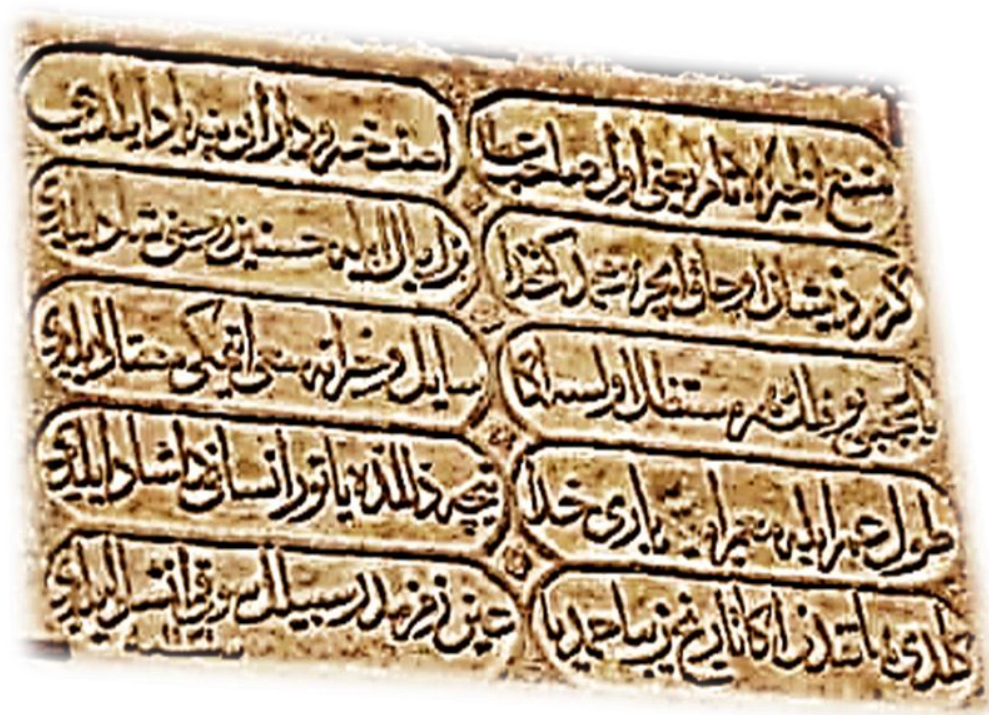

سبيل أحمد أفندى سليم: 
جاء البيت الأخير من هذا النص :

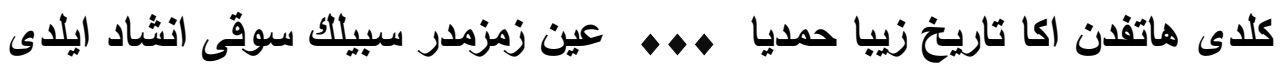

\section{سنة 1131}

لقد حاولنا تطبيق أنواع التواريخ المختلفة للحصول على تاريخ الإنثاء الصحيح لهذا السبيل، وهو كما نُقش بنهاية اللوحة التأسيسية سنة ( 1131هـ)، فحاصل جمع حروف الثطر الأخير يساوى (1137هـ) وهو التاريخ نفسه الذى جاء فى بعض المصادر والمراجع التاريخية(25)، على الرغم من أن التاريخ المنقوش واضح (1131هـ)؛ لكن تلك المصادر اعتمدت على حساب الجُمّل وعدُّوا حاصل جمع هذه الحروف هى التاريخ الصحيح، بيد أن فى كلمة (سوقى) فى لي المصراع الأخير من البيت يُرجّح أن الخطاط الذى خطّها على اللوحة التأسيسية للسبيل قد كتبها بشكل خاطئ، وما يُدعم هذا الترجيح أن كلمة (سوقى) لا تتوافق مع وزن البيت، ولا تتفق دلالتها مع السياق، والراجح أن الثاعر قد نظم نصه بكلمة ( سقي ) والتى تعنى هنا " سقاية العطاثى " والتركيب "سبيلك سقي" مقصود به هنا ماء السبيل الذى اسقى العطاثى. وهذا النص من بحر الرمل على وزن ( فاعلاتن فاعلاتن فاعلاتن فاعلن )، وبتقطيع المصراع الأخير وبخاصة تفعيلة فاعلاتن مع كلمة سقى وكلمة سوقى نجد أن سقى تتطابق مع الوزن على النحو التالى:

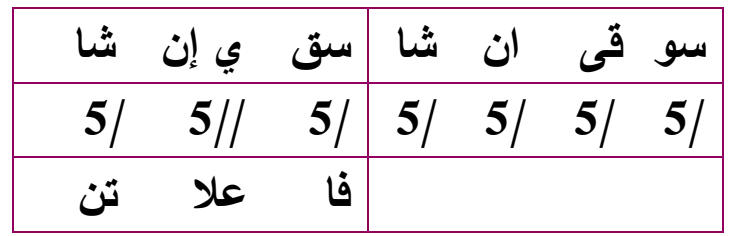

ونتيجة لذلك نقوم بحذف حرف ( الواو ) الزائد والذى يوافق القيمة العددية للرقم (6)، ثم نحسب القيمة العددية لحاصل جمع حروف الثطر الأخير بكلمة ( سقى) لنحصل على التاريخ التام لإنشاء السبيل وهو (1131هـ) وذللك على النحو التالى:

\begin{tabular}{|c|c|c|c|c|c|c|}
\hline إيلدى & ا ل اثشاد & سقى & سبيك & زمزمدر & عين & الكلمة \\
\hline 55 & 356 & 170 & 122 & 298 & 130 & القيمة العددية \\
\hline \multicolumn{6}{|c|}{1131} & المجموع \\
\hline
\end{tabular}




\section{2. تاريخ التعمبة (تعميه لى تاريخ):}

لقد وُضنَح معنى التعمية لغةً واصطلاحًا من قبل، وذُكر أن ضروبها أصبحت أساس فن

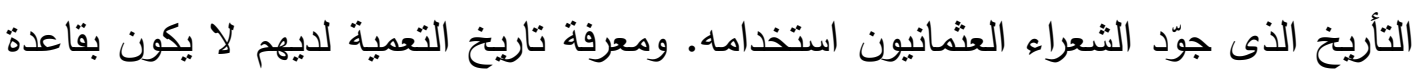
محددة، ولكن يعتمد استخراجه على عدة طرق منها الواضحة اليسبرة، ومنها ما تعتمد على خبرة مُستخرج هذا التاريخ المُعمى وفطنته. وفى الواقع كان هناك صعوبة فى استخراج بعض التواريخ

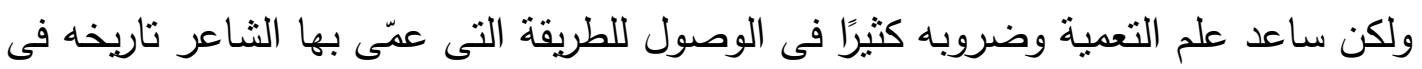
النص، وتعريف تاريخ التعمية: هو التاريخ الذى لانوافق القيمة العددية لحروفه التاريخ المراد

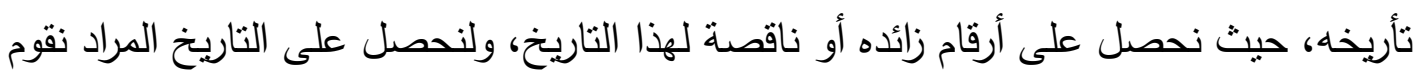

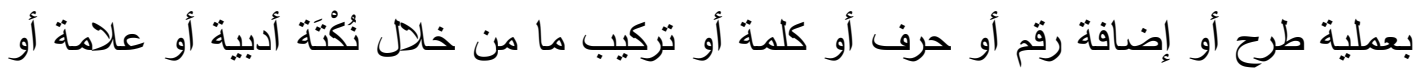

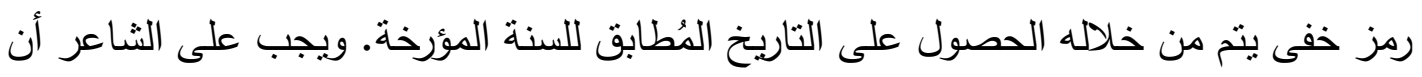

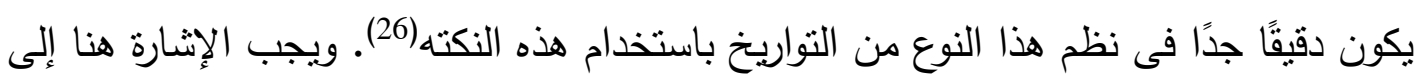

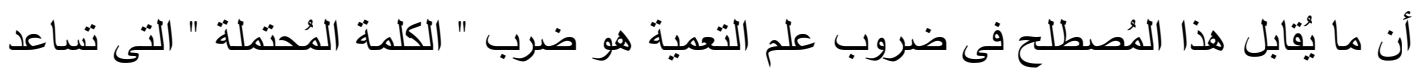

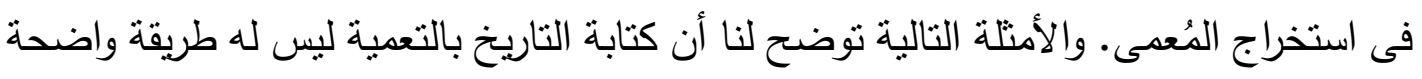

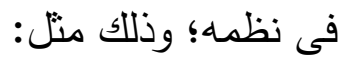
شكل كرداب كلير فكره يازاركن تاريخ ... سوردى يلكن كورث اعدايى قبودان باشا سنة

\section{4}

لقد أُرخ بالتعمية فى هذا البيت؛ فعند جمع القيمة العددية لحروف المصراع الأخير نحصل

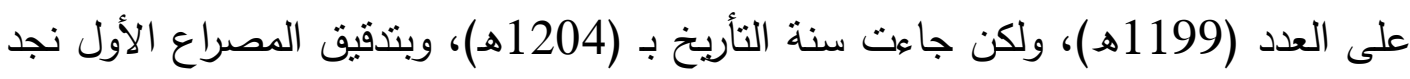

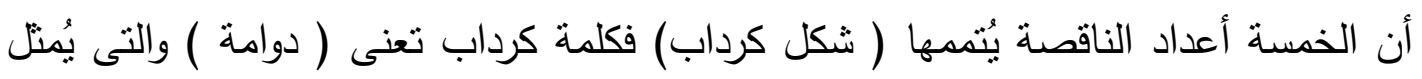

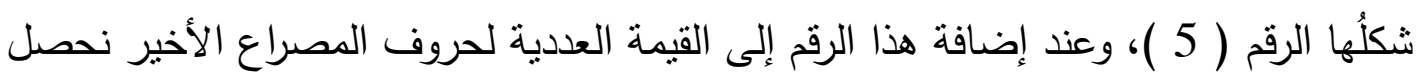
على سنة النأريخ (1204هـ) (27).

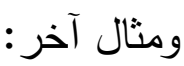


نهله فلكدن كوشمه تاريخ منقوطلك كلير +... الليسندن صكره اوكسوز قويدك آنه اوغلنى

\section{سنة 1346}

فى هذا المثال جاء حساب القيمة العددية للحروف المنقوطة فى المصراع الأخير وهى (ب، ن، ن، ز، ق، ي، ن، غ، ن، ي) مساويًا: ( 1337) والذى ينقص تسعة أعداد عن سنة التأريخ وهى (1346هـ)، نجد فى المصراع الأول كلمة ( نه) تُعطى القيمة العددية للرقم (9)، فهى تعنى العدد (9) باللغة الفارسية، وعند إضافة قيمتها العددية إلى القيمة العددية للحروف المنقوطة فى المصراع الأخير؛ نحصل على سنة التأريخ المراد تأريخها ( 1337+9 = 1346)(28). ما سبق كانت أمتلة لتعمية التاريخ، فبعد الوصول للقيمة العددية للتاريخ نبحث عن الكلمة المحتملة التى يُؤرخ بها، فكانت فى المثال الأول (كرداب)، وفى المثال الثانى (نه)، ويوجد طُرق أخرى عُمى بها التاريخ ستُّكر من خلال رصد تواريخ التعمية التى نُظم بها فى تأريخ بعض الأسبلة والتى نجد أنها تتقسم لقسمين؛ الأول: يسهُل الوصول إليه من خلال ذكر الثاعر الرقم الناقص أو الزائد فى مصراعٍ أو فى بيتٍ نستطيع من خلاله الوصول للسنة المراد تأريخها. والثانى: يصعُب استخراجه؛ إذ يستخدم الثاعر نوعًا من أنواع التواريخ المختلفة ولا يكتفى بها فحسب بل يجعلنا نبحث عن الكلمة المُحتملة التى بها يكتمل التاريخ ونحصل على التاريخ المراد تأريخه. ولكى يتضح هذا النوع من التواريخ ويُطبَّق على النصوص المُؤرخة به لا بد من التعريف بأنواع التواريخ الأخرى التى استُخدمت فى تعمية التاريخ ومن ثم التطبيق. ونذكر منها:

\section{أولَا: تاريخ الصروف المكرة ( مكرر حرفلرله تاريخ ):}

وهو ذلك التاريخ الذى يُسقط بحساب الحروف التى استخدمها الثاعر مرتين على الأقل فى نظم تاريخه فى مصراعٍ أو بيتٍ فى النص الذى يحمل التاريخ(29). وقد استخدم هذا النوع فى تعمية التاريخ على النحو التالى: 


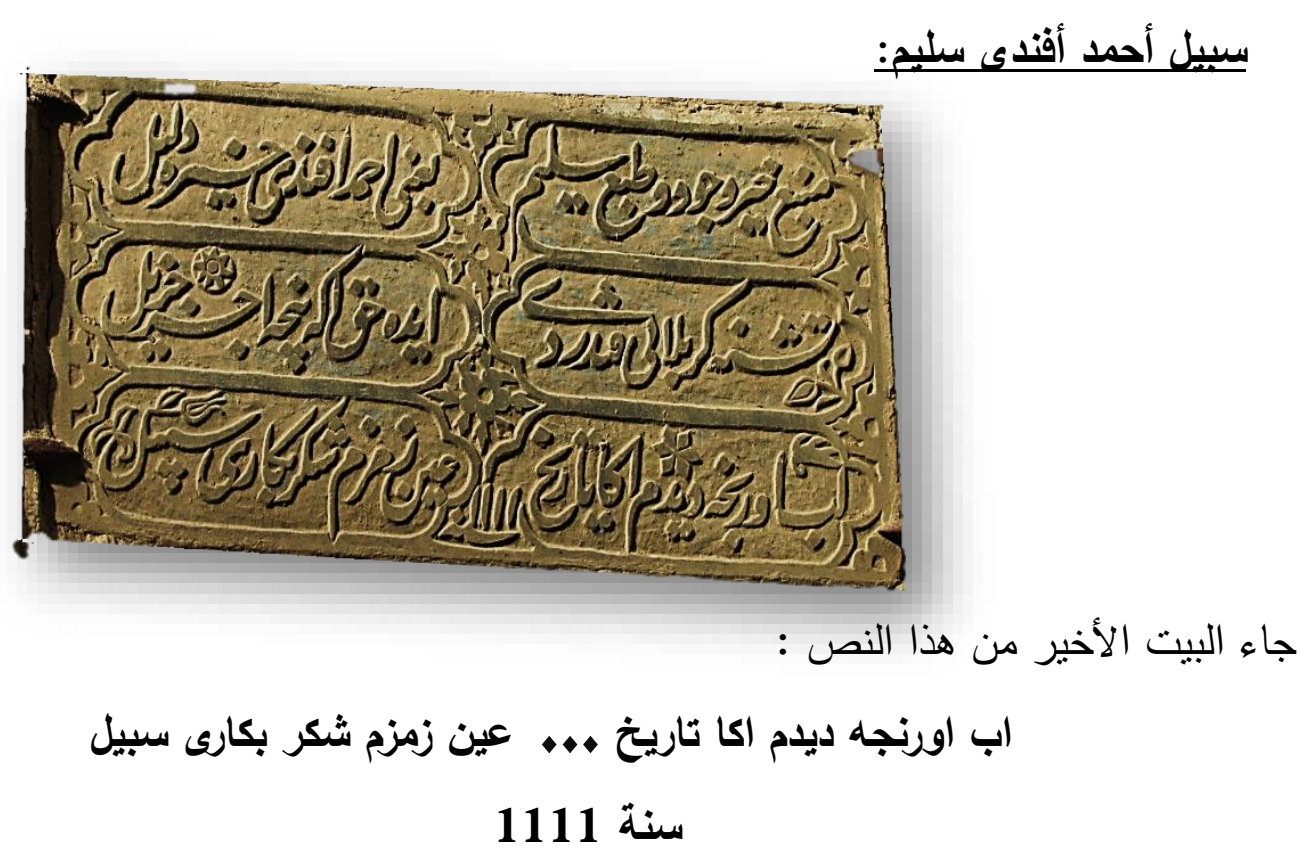

لقد حاولنا تطبيق أنواع التواريخ المختلفة للحصول على تاريخ الإنشاء الصحيح لهذا السبيل، وهو كما نقته بنهاية اللوحة التأسيسية سنة ( 1111هـ)، بيد أننا لم نحصل على التاريخ إلا باستخدام نوعين من أنواع التواريخ معًا، وهما: التاريخ بحساب الحروف التى تكررت على الأقل مرتين فى البيت الأخير ، بالإضافة إلى ناريخ التعمية وفيه نبحث عن النكتة أو الرمز الخفى أو الكلمة المحتملة التى يُحصل بها على سنة الإنشاء لهذا التاريخ وذلك على النحو التالى: - الحروف المكررة في البيت الأخير هي:

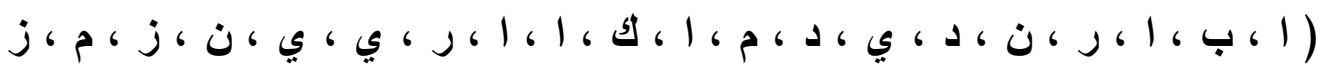

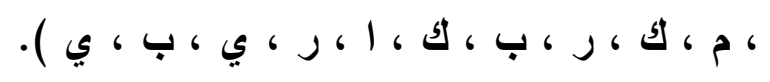

$$
\begin{aligned}
& \text { - والقيمة العددية لهذه الحروف هي: } \\
& 200+1+1+20+1+40+4+10+4+50+200+1+2+1) \\
& 200+1+20+2+200+20+40+7+40+7+50+10+10+ \\
& \cdot(10+2+10+
\end{aligned}
$$


وحاصل جمع القيمة العديدية لهذه الحروف المكررة هو ( 1164 )، والذى لا يوافق سنة إنشاء السبيل، وهى (1111هـ )، إذ إن هذه القيمة العددية تزبد على تاريخ الإنشاء بنحو (53) رقم. وهنا تأنى أهمية استخراج الكلمة المحتملة والتى ينبغى أن يكون حاصل جمع القيمة العددية لحروفها مساويًا للرقم ( 53 ) ) وقد وجدنا أن الكلمة المُحتملة مُمنتلة فى اسم مُنشئ السبيل وهو ( احمد ) والذى يُطابق قيمته العددية الرقم ( 53 )، ودل ذلك من ذكر الثاعر لكلمة (اكا) فى المصراع الأول، أى لـ ( أحمد ) مُنشئ السبيل وذلك كما يلى :

\begin{tabular}{|c|c|c|c|c|}
\hline د & م & $\tau$ & 1 & حروف (احمد) \\
\hline 4 & 40 & 8 & 1 & الميمة العددية \\
\hline \multicolumn{4}{|c|}{53} & المجموع \\
\hline
\end{tabular}

هنا بعد الوصول إلى القيمة العددية لحاصل جمع الحروف المكررة (1164)، والقيمة العددية لحاصل جمع الكلمة المُحتملة (53)؛ نقوم بعملية حسابية أخرى وهى عملية الطرح لنحصل على التاريخ الصحيح لإنشاء السبيل على النحو التالى : 11

\section{$1111=53-1164$}

\section{ثنانيًا: تاريخ الحروف المُهملة (تاريخت مهمل):}

يُطلق على هذا التاريخ أيضًا: ( بى نقط، بى جوهر ، ساده تاريخ ) أى: ( بدون نقط، بدون جوهر، تاريخ بسيط) ، فهو ذلك التاريخ الذى يُكن الحصول عليه بحساب الحروف غير المنقطوطة، ويُعد نظم التاريخ بهذا النوع شديد الصعوبة(30). ونجد هذا النوع قد استُخدم فى بـ تعمية التاريخ على النحو التالى: 


\section{سبيل محمد على (النحاسين) :}

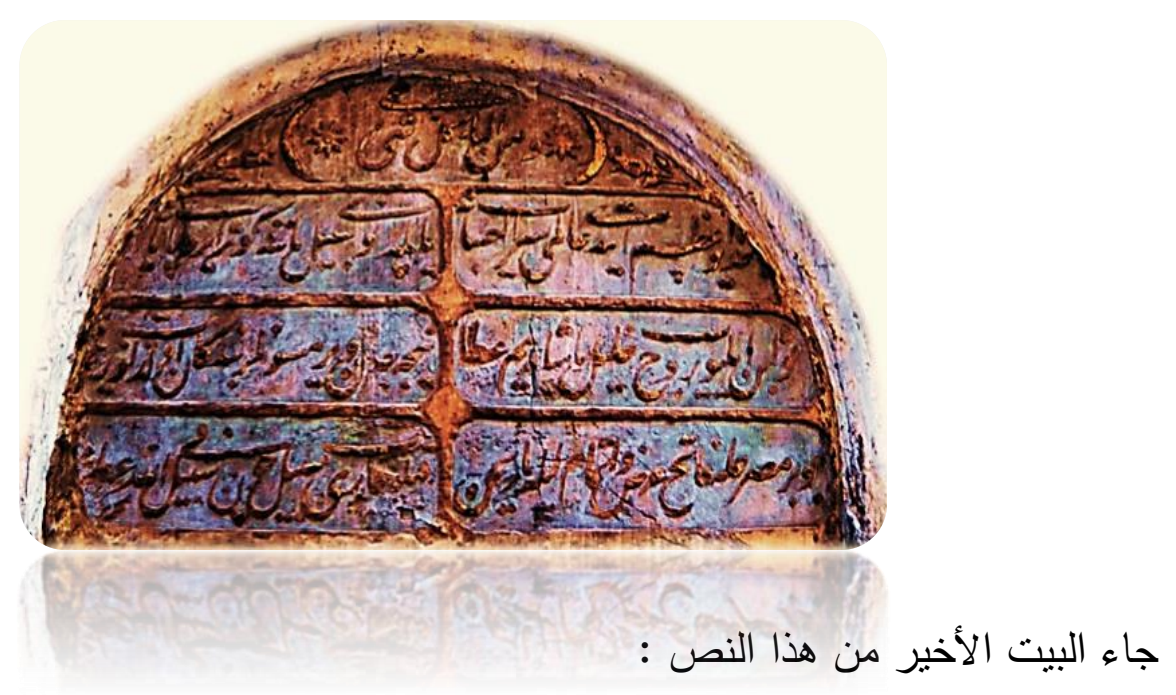

بو بر مصرعله فاتح عرض واتمام ايله تاريخن

قيلوب جارى سبيل جون فى سبيل الله عطشانه

فى هذا البيت أرشد فاتح ( ناظم هذا التاريخ ) إلى أنه تاريخ إنثاء السبيل المصاصة يُحسب من خلال المصراع الأول فقط من هذا البيت، ولكنه لم يُشُشد على نوع التاريخ المستخدم. وبعد تطبيق أنواع التواريخ المختلفة للحصول على تاريخ الإنشاء الصحيح، وهو سنة (1244هـ)، وجدنا أنه نُظِم التاريخ باستخدام نوعين من أنواع التواريخ معًا، وهما: التاريخ بحساب الحروف المُهملة فى المصراع الأول، بالإضافة إلى تاريخ التعمية، وفيه نبحث عن النكتة أو الرمز الخفى أو الكلمة المحتملة التى يُحصل بها على سنة الإنشاء لهذا التاريخ وذلك

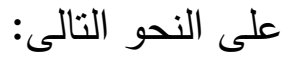
- الحروف المُهملة في المصراع الأول:

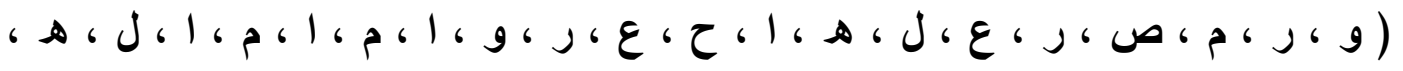
$\cdot(\jmath \cdot 1$ 
- والقيمة العددية لهذه الحروف هيى:

$+6+200+70+8+1+5+30+70+200+90+40+200+6)$

$$
\cdot(200+1+5+30+1+40+1+40+1
$$

وحاصل جمع القيمة العديدية لهذه الحروف المهملة هو ( 1245 )، والذى لا يوافق سنة إنثاء السبيل وهى (1244هـ )، إذ إن هذه القيمة العددية تزبد على تاريخ الإنشاء برقم واحد. وباستخراج الكلمة المحتملة والتى ينبغى أن تُعطينا القيمة العددية لها الرقم ( 1 ) ، وجدنا أن الكلمة المُحتملة مُمنلة فى كلمة ( بر ) من المصراع نفسه، فهذه الكلمة بها تورية ففى حين أنها أداة تتكير لكلمة " مصراع " إلا أنها تعنى الرقم " واحد " أيضًا فقى التركية العثمانية يُكتب الرقم واحد ( بر ) ، وهو هنا الكلمة المُحتملة التى ثُطابق القيمة العددية التى نبحث عنها وهى (1). إذًا بعد الحصول على القيمة العددية لحاصل جمع الحروف الئهملة (1245)، والقيمة العددية للكلمة المحتملة المُمنلة فى كلمة ( بر = ا )؛ نقوم بعملية حسابية أخرى وهى عملية الطرح لنحصل على التاريخ الصحيح لإنشاء السبيل على النحو التالى :

\section{$1244=1-1245$}

ثالثًا: تاريخ الحروف المُعجمة ( Mu’cem tarih)؛ هو ذلك التاريخ الذى يُمكن الحصول عليه بحساب الحروف المنقطوطة(31). وقد استُخدم هذا

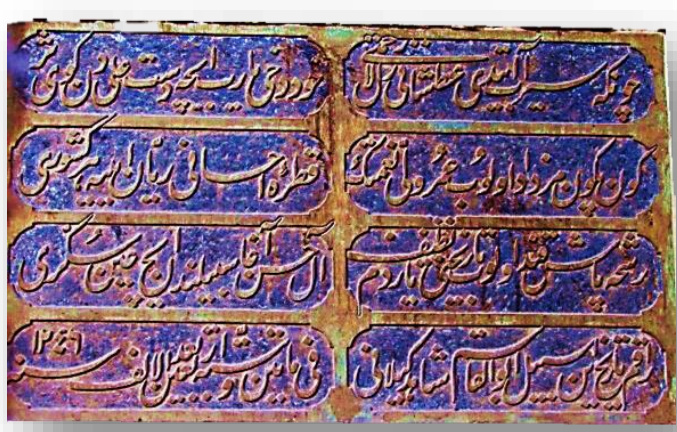
النوع فى تعمية التاريخ على النحو التالى: سبيل حسن آغا ارزنكان: جاء البيت الأخير من هذا النص : رشحه ياش قند اولوب تاريخنى يازدم نظيف ـ... آل حسن آغا سبيلندن ايتج عين سكرى سنة 1246 
بعد تطبيق أنواع التواريخ المختلفة للحصول على تاريخ الإنثاء الصحيح، وهو سنة (1246هـ)، وُجد أن التاريخ نُظم باستخدام نوعين من أنواع التواريخ معًا، وهما: التاريخ بحساب الحروف المُعجمة (المنقوطة) فى المصراع الأخير من هذا البيت، بالإضافة إلى تاريخ التعمية وفيه نبحث عن النكتة أو الرمز الخفى أو الكلمة المحتملة التى يُحصل بها على سنة الإنثاء لهذا التاريخ وذلك على النحو التالى: - الحروف المُعجمة فى المصراع الأخير:

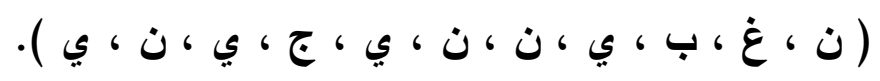
- والقيمة العددية لهذه الحروف هي: $\cdot(10+50+10+3+10+50+50+10+2+1000+50)$

وحاصل جمع القيمة العددية لهذه الحروف المُعجمة هو ( 1245 ) والذى لا يوافق سنة إنشاء السبيل وهى (1246هـ )، إذ إن هذه القيمة العددية تتقص عن تاريخ الإنشاء برقم واحد. وباستخراج الكلمة المحتملة والتى ينبغى أن تُعطينا القيمة العددية لها الرقم ( 1 ) ، وجدنا أن الكلمة المُحتملة مُمثلة فى كلمة ( رشحه ) فى المصراع الأول من هذا البيت، فهذه الكلمة تعنى ( قطرة ) ، وقد قصد بها الثعر رقم (1) وبناءً على ذلك؛ هذه هى الكلمة المُحتملة التى تُطابق القيمة العددية التى نبحث عنها وهى (1). إذًا بعد الحصول على القيمة العددية لحاصل جمع الحروف المُعجمة (1245)، والقيمة العددية للكلمة المحتملة المُمتلة فى كلمة ( رشحه = I )؛ نقوم بعملية حسابية أخرى وهى عملية الجمع لنحصل على التاريخ الصحيح لإنشاء السبيل على النحو التالى: 1245 + 1 = 1246 أما السطر الذى يلى البيت الأخير من النص وهو : ( راقم تاريخ اين سبيل ابو القاسم شاهد كيلانى فى مائتين وستة واربعين بعد الألف سنة 1246 ) فيخبرنا أن كاتب - أى الخطاط الذى خطَّ - تاريخ هذا السبيل هو أبو القاسم شاهد الكيلانى، وكتابة التاريخ ملفوظًا بالحروف والأرقام 
Lafzen ve Manen - هكذا، يُعد نوعًا من أنواع التواريخ وهو (التاريخ ذو اللفظ والمعنى

${ }^{(32)}$ ( Tarihler

إلى هنا نكون قد ذكرنا أنواع التاريخ المُعماة التى يصعُب استخراجها من خلال النصوص المذكورة؛ حيث يستخدم الثاعر نوعًا من أنواع التواريخ المختلفة، ولا يكتفى بها فحسب؛ بل يجعلنا نبحث عن الكلمة المُحتملة التى بها يكتمل التاريخ ونحصل على التاريخ المراد تأريخه. أما عن النوع الآخر الذى يسهُل الوصول إليه من خلال حذف حرف زائد على كلمة ما أو ذكر الثاعر الرقم الناقص أو الزائد فى مصراعٍ أو فى بيتٍ فنستطيع من خلاله الوصول للسنة المراد تأريخها؛ وذللك بإجراء عملية حسابية سواء كانت طرحًا أو جمعًا للعدد المذكور بصورة مباشرة فى المصراع الأول من البيت الأخير، وهذا العدد بمثابة الكلمة المحتملة التى نبحث عنها ولكننا نصل إليها بسهولة كما يلى: النص الذى يعلو السبيل المصاصة المُلحق بسبيل محمد على ( العقادين): جاء البيت الأخير من هذا النص : دوشدى فاتح قطره وش تاريخ دو شق خامه دن ... افديرر جو حاصلى بزيوزه مانند حيات

\section{سنة 1254}

لقد ذكرنا سلفًا أن التاريخ فى هذا النص جاء بنوعين من التواريخ، الأول: التاريخ التام، وقد وضحنا ذللك فى موضعه. وذللك إذا حسبنا جميع الحروف فى المصراع الأخير كما هى فنحصل على التاريخ الأصلى لإنشاء السبيل وهو (1236هـ)، ولكن الثاعر أبدع فى نظم تاريخه لتأريخ السبيل المصاصة الذى أُنشئ سنة (1254هـ) كما نُقش بنهاية النص، واستخدم نوعًا آخر من التواريخ؛ ألا وهو تاريخ التعمية حيث إنه استخدم من ضروب علم التعمية ضرب التعمية بالإعاضة أو التبديل، أى تبديل الحروف بحروف أخرى، فأصل كلمة (افديرر) هنا ( اقديرر) والتى تتوافق مع معنى البيت، ولكنه بدّل حرف القاف بحرف الفاء لكى نحصل على تاريخ إنشاء السبيل الأصلى وتاريخ انشاء السبيل المصاصة الذى أُلحق بعمارة السبيل فى عام (1254هـ)، 
والواقع " فاتح " ناظم هذا النص قد لمّح لنا بذلك فى المصراع الأول من هذا البيت. ويتضح هنا من ذكر شقين؛ أنه أرخ تاريخين كما أسلفنا الذكر. والجدول التالى هو توضيح لتاريخ التعمية، حيث نحسب المصراع الأخير بالكلمة الأصلية وهى (اقديرر)، ثم نبحث عن الكلمة المُحتملة التى يتم بها التاريخ وهو سنة (1254) كما تم نقشه بنهاية النص وذللك كما يلى:

\begin{tabular}{|c|c|c|c|c|c|c|}
\hline هيات & مانتد & بزيوزه & حاصلى & جو & اقدير & الكلمة \\
\hline 419 & 145 & 29 & 130 & 9 & 515 & قيمتها العددية \\
\hline \multicolumn{6}{|c|}{1256} & المجموع \\
\hline
\end{tabular}

نجد هنا أن حاصل جمع القيمة العديدية لحروف المصراع الأخير هو ( 1256 )، والذى لا يوافق سنة إنثاء السبيل وهى (1254هـ )، إذ إن حاصل جمع هذه القيمة العددية نزبد على تاريخ الإنشاء برقمين. وباستخراج الكلمة المحتملة والتى ينبغى أن تُعطينا القيمة العددية لها الرقم ( 2 ) ، وجدنا أن الكلمة المُحتملة مُمتلة فى كلمة ( دو ) فى المصراع الأول من هذا البيت، فهذه الكلمة تعنى ( اثثين ) باللغة الفارسية، وبناءً على ذلك؛ هذه هى الكلمة المُحتملة التى نُطابق القيمة العددية التى نبحث عنها وهى (2). إذًا بعد الحصول على القيمة العددية لحاصل جمع حروف المصراع الأخير (1256)، والقيمة العددية للكلمة المحتملة المُمتلة فى كلمة ( دو = 2 )؛ نقوم بعملية حسابية أخرى وهى عملية الطرح لنحصل على التاريخ الصحيح لإنثاء السبيل على النحو التالى :

$$
1254=2-1256
$$

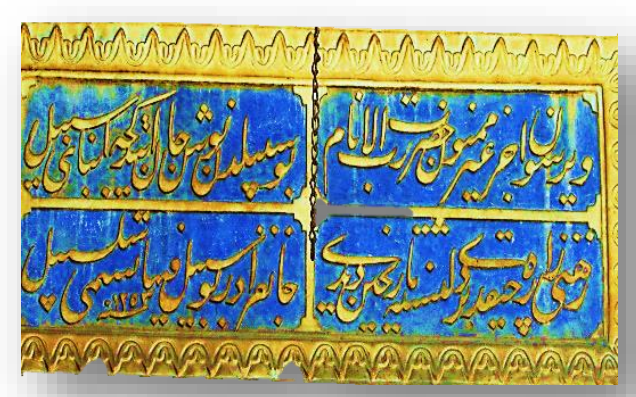

سيل سليمان آغا السلحدار: 
جاء البيت الأخير هن هذا النص :

زهنى زاره جيقدى بر دلتشنه تاريخين ديدى ... جانفزادر بو سبيل فيها تسمى سلسبيل

\section{سنة 1253}

لقد استخدم الثاعر تاريخ التعمية فى نظم تاريخه لتأريخ هذا السبيل الذى أُنشئ سنة (1253هـ) كما نُقش بنهاية النص، وفى الجدول التالى سنحسب المصراع الأخير، ثُ نبحث عن الكلمة المُحتملة التى يتم بها التاريخ وهو سنة (1253) وذلك كما يلى:

\begin{tabular}{|c|c|c|c|c|c|c|}
\hline سلسبيل & تسمى & فيها & سبيل & بو & جانفزادر & الكلمة \\
\hline 192 & 510 & 96 & 102 & 8 & 146 & قيمثها العددية \\
\hline \multicolumn{6}{|c|}{1254} & المجموع \\
\hline
\end{tabular}

نجد هنا أن حاصل جمع القيمة العديدية لحروف المصراع الأخير هو ( 1254 ) والذى لا يوافق سنة إنشاء السبيل وهى (1253هـ )، إذ إن حاصل جمع هذه القيمة العددية تزبد على تاريخ الإنشاء برقم واحد. وباستخراج الكلمة المحتملة والتى ينبخى أن تُعطينا القيمة العددية لها الرقم ( 1 ) ، وجدنا أن الكلمة المُحتملة مُمتلة فى كلمة ( بر ) فى المصراع الأول من هذا البيت، فهذه الكلمة تعنى ( واحد )، وبناءً على ذلك؛ هذه هى الكلمة المُحتملة التى نُطابق القيمة

$$
\text { العددية التى نبحث عنها وهى (1). }
$$

إذًا بعد الحصول على القيمة العددية لحاصل جمع حروف المصراع الأخير (1254)، والقيمة العددية للكلمة المحتملة المُمتلة فى كلمة ( بر = 1 )؛ نقوم بعملية حسابية أخرى وهى عملية الطرح لنحصل على التاريخ الصحيح لإنشاء السبيل على النحو التالى:

$$
1253=1-1254
$$

3. التاريخخ المُعجم (تاربخ مجوهر - تاريخخ معجم):

ذكرنا التاريخ المُعجم حين تحدثا عن أنواع التواريخ التى استخدمت فى تاريخ التعمية وقد أفردنا الحديث هنا عن هذا النوع مجددًا ذلك لأنه قد نُظم بهذا التاريخ فى بعض نصوص الأسبلة 
كتاريخ مستقل بذاته، وكما ذكرنا هو التاريخ الذى يُنظم بحساب الحروف المنقوطة فقط فى المصراع أو البيت الذى يحمل التاريخ. يُطلق على هذا التاريخ أيضًا: ( منقوط - menkūt )،

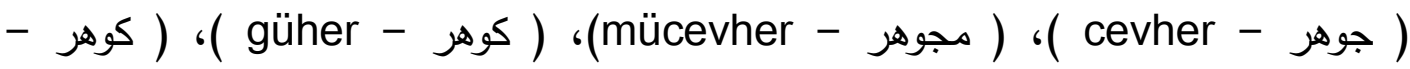
(33)(cevher البيت الذى يلى التاريخ المنظوم، فذكر أحد هذه الكلمات تدُلنا على طريقة الثاعر فى نظم تاريخه، فنصل إلى نوع التاريخ بسهولة وذلك كما يلى: سيبل محمد على (العقادبن):

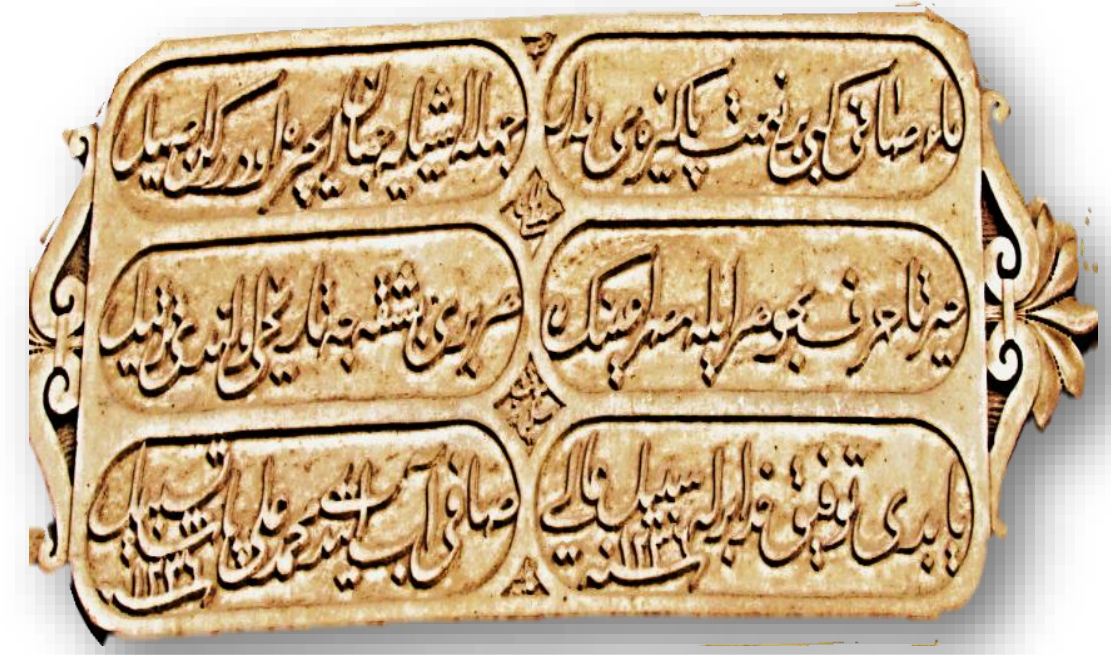

هنا نذكر البيت ما قبل الأخير والبيت الأخير من هذا النص:

حيرتا حرف مجوهر ايله مصراعينك ـ... هر برى بشقه جه تاريخى اولنده ترتيل يابدى توفيق خدا بر له سبيل عالى هـ.. صافى آب ايتدى محمد على باشنا تسبيل سنة 1236 سنة 1236

\section{الترجمة:}

يا حيرت: إن مصراعيه كُتبا بحروف الجوهر .... وكل مصراع فيه تاريخه مختلف الترتيل بتوفيق الله شُيد بالبر هذا السبيل العظيم .... وجعل محمد على باشا الماء الصافى تسبيلا سنة 1236 سنة 1236 
بتضح هنا أن ناظم التاريخ قد أرشدنا إلى معرفة نوع التاريخ الذى نظم بها ناريخه، فمن خلال ذكره لكلمة (مجوهر) وتوضيحه بأنه منظوم فى مصراعيّ بيت التاريخ ؛ علمنا أن التاريخ يجب حسابه بجمع القيمة العددية للحروف المنقوطة فى كل مصراع على حدة، وقد وافقت القيمة العددية للحروف المنقوطة فى كل مصراع تاريخ إنشاء السبيل وهو سنة (1236هـ) على النحو التالى :

$$
\begin{aligned}
& \text { - الحروف المُعجمة في المصراع الأول: }
\end{aligned}
$$

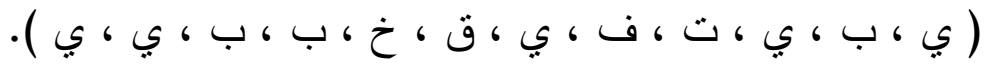

$$
\begin{aligned}
& \text { - والقيمة العددية لهذه الحروف هي: } \\
& \cdot(10+10+2+2+600+100+10+80+400+10+2+10) \\
& \text { وحاصل جمع القيمة العديدية لهذه الحروف المُعجمة هو ( } 1236 \text { ). } \\
& \text { - الحروف المُعجمة في المصراع الثانى: } \\
& \text { ( ف ، ي ، ب ، ي ، ت ، ب ، ي ، ب ، ش ، ت ، ب ، ب ). } \\
& \text { - والقيمة العددية لهذه الحروف هي: } \\
& \cdot(10+2+400+300+2+10+10+400+10+2+10+80)
\end{aligned}
$$

وحاصل جمع القيمة العديدية لهذه الحروف المُعجمة هو ( 1236 ). ويجدر بنا الإشارة أن نظم الثاعر تاريخه مرتين بهذه الصورة لا بعنى أنه قد نظم بما يُطلق عليه بتاريخ دوتا (34) (Dü-tâ tarih)، والذى يُسمى أيضًا ( muzâaf tarih) ) أى (تاريخ مضاعف )، وهو ذلك التاريخ الذى يثمل المصراع الواحد فيه على تاريخين، حيث يكون حاصل جمع حروف المصراع الواحد يُعطى ضعف السنة المراد تأريخها، فيُجزَّاً المصراع إلى قسمين، كل قسم منهما يحمل سنة التاريخ بشكل منفصل(35). أما هنا فى هذا النص فلم بنظم الثاعر تاريخ إنشاء السبيل فى مصراعٍ واحد يحمل ضعف تاريخ ( 1236)؛ بل أظهر مهارته فقط فى 
نظم التاريخ مرتين باستخدام حروف مُعجمة مختلفة تُعطى لنا التاريخ نفسه من خلال بيتٍ كامل، وليس من خلال مصراع فقط. سبيل والدة مصطقى باشا فاضل:

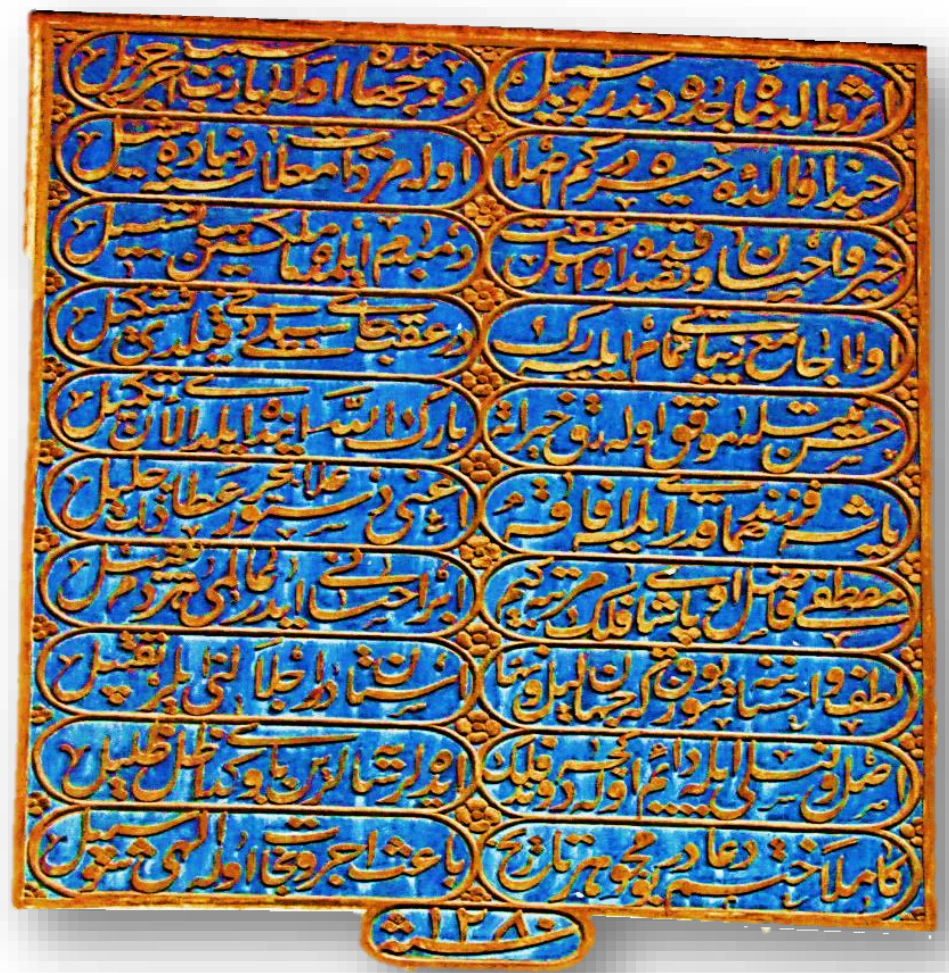

جاء البيث الأخير من هذا النص: كاملا ختم دعادر بو مجوهر تاريخ ه... باعث اجر ونجات اوله الهى شو سبيل

\section{سنة 1280}

أرشد ناظم التاريخ لهذا النص إلى معرفة نوع التاريخ الذى نظم بها تاريخه، فمن خلص ذكره لكلمة (مجوهر ) علمنا أن التاريخ يجب حسابه بجمع القيمة العددية للحروف المنقوطة فى المصراع الأخير فقط، وقد وافقت القيمة العددية للحروف المنقوطة فيه تاريخ إنشاء السبيل وهو سنة (1280هـ) وذلك على النحو التالى: - الحروف المُعجمة في المصراع الأخير: ( ب ، ث ، ج ، ن ، ج ، ت ، ي ، ش ، ب ، ي ). 


$$
\begin{aligned}
& \text { - والقيمة العددية لهذه الحروف هي: } \\
& \cdot(10+2+300+10+400+3+50+3+500+2) \\
& \text { وحاصل جمع القيمة العديدية لهذه الحروف المُعجمة هو ( } 1280 \text { ). }
\end{aligned}
$$

ننتهى إلى هنا من ذكر فن التأريخ وأنواعه التى نُظم بها التاريخ فى النصوص الثعرية التى لهى دوُنت على الأسبلة التى أُنشت فى العهد العثمانى؛ بيد أنه يوجد أنواع أخرى قد نُظم بها التاريخ ولكن لم تشملها النصوص موضوع الدراسة، ولكى نُلم بأنواع هذا الفن كافة نذكرها فيما يلى : - تاريخ الحروف غير المكرة (Gayri Mükerrer Harflerle Tarih ) هو نوع من التواريخ الذى يُنظم فيه التاريخ بحساب الحروف التى ذُكرت مرة واحدة فى بيت التاريخ أو مصراعه(36)، وهذا النوع عكس التاريخ بحساب الحروف المكررة. - تاريخ الحروف الموصولة (Muvassal Harflerle Tarih ): هو التاريخ الذى يُنظ فيه التاريخ بحساب الحروف الموصولة ببعضها فى الكلمة دون حساب الحروف المفردة غير الموصولة فيها، ونذكر البيت التالى الذى يحمل مصراعه الأول سنة التاريخ وهى (1023هـ) على النحو النالى: رياست صدر افندى سمعى دارات وعطا جاين نوله لطف اي دوب احيا إبلسه بو صاحب شاندر

فإذا حسبنا الحروف الموصّّة فى المصراع الأول وهى ( ياست صدفنى سمعى عطا جاين) نحصل على القيمة العددية بحاصل جمع هذه الحروف والتى توافق سنة (1023هـ). - تاربخ الصوف المُقطعة ( Mukatta'a (Kesik) Harflerle Tarih ) ان الحساب بهذا التاريخ يكون عكس الحساب الذى نقوم به فى التاريخ بحساب الحروف الموصولة؛ حيث الذى يُنظم فيه التاريخ بحساب الحروف المُقطعة فقط فى الكلمة وإهمال حساب الحروف الموصولة فيها، ونذكر البيت السابق أيضًا فمصراعه الأول يحمل هذا النوع أيضًا من التاريخ على النحو التالى: 
رياست صدر افندى سمعى دارات وعطا جاين

\section{نوله لطف اي دوب احيا إيلسه بو صاحب شاندر}

فإذا حسبنا الحروف المُقطعة فى المصراع الأول وهى ( ر ر اي د ار ات ت و ) نحصل على القيمة العددية بحاصل جمع هذه الحروف والتى توافق سنة (1023هـ)(37). - التواريخ الغامضة /تاريخ الألغاز (Bilmeceli Tarihler ) هو نوع من التواريخ الذى لـ يُستخدم فى التعمية بحساب ابجد ويكون فى دلالتها إثنارة إلى اسم إنسان (38)، ونستطيع القول إن هذا النوع قد استخدم فى تعمية التاريخ لسبيل أحمد أفندى سليم. - تواريخ الشطرنج ( Satranç Usulü Tarih) فى هذا النوع تمنل الأبيات مربعات الثطرنج، فعند حساب التاريخ فيها من أعلى إلى أسفل، ومن الأسفل إلى الأعلى، ومن اليسار إلى اليمين، ومن اليمين إلى اليسار ؛ نحصل على سنة التأريخ، وهو من الأنواع الصعبة جدًا التى يُنظم بها التاريخ (39). بعد هذا السرد لفن التأريخ وأنواعه المختلفة التى نُظم بها التواريخ؛ يتضح جليًا العلاقة بين هذا الفن وبين ضروب علم التعمية، وما يُلفت الانتباه أن الشعراء العثمانيين قد أطلقوا لفظ (التعمية) على نوع من أنواع التواريخ التى نظموا بها، ولكن أثتتت الدراسة أن كل الأنواع التى كُتب بها التاريخ لها صلة وثيقة بضروب علم التعدية، ويُجدر الإثارة إلى أن العرب قد نظموا تواريخه وأبدعوا فى استخدام أنواع مختلفة من التواريخ(40)، وذلك عكس ما ذكر طاهر المولوى بأن الأدب العربى لا يوجد به هذا الفن(41). 


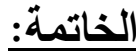

بعد هذا السرد لفن التأريخ نخلص إلى عدة نتائج:

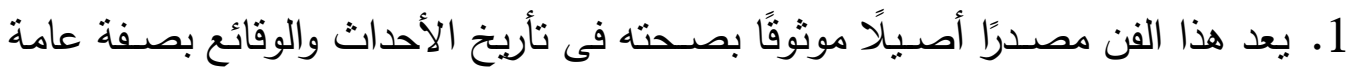
والمنشآت المعمارية بصفة خاصة. 2. إن فن التأريخ ضـرب من ضـروب علم التعمية ، وإن أنواع هذا الفن ذات صـلة قوية بأنواع علم التعمية وضروبه، ونُجمل القول بأن الثعراء الأتراك أثروا تقافتهم باطلاعهم

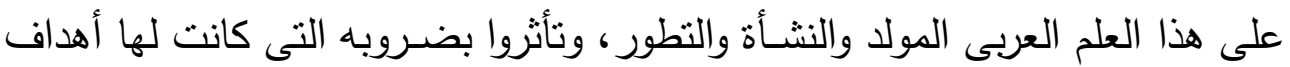
أخرى عند العرب، فنقلوها إلى أدبهم، ووظقّوها فى أثــــعارهم، حيث جعلوها أنواعًا لتواريخهم التى نظموا بها بمهارة وفطنة، وبنهج مبنكر ـ وهم بذلك لم يكتفوا بالنقل فقط ولكن طوروا ما نقلوه وبلغوا به حد الابتكار والإبداع.

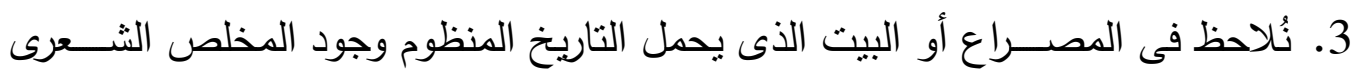
لناظم التاريخ فى أغلب النصوص موضوع الدراسة.

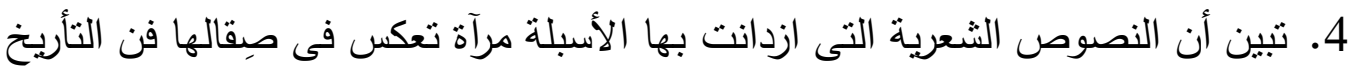

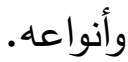




\section{الهوامش والحواشي

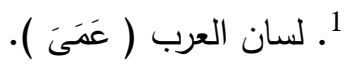

2. - محمد مراياتى، يحيى مير علم وآخرون، علم التعمية واستخراج المعىى عند العرب، ج (1)، مطبوعات مجمع اللغة العربية بدمشق، 1987م، ص 9، 28، 38، 42، 43، 74، 150، 224. - محمد مراياتى، يحيى مير علم وآخرون، علم التعمية واسـتخراج المعمى عند العرب (التشـفير وكسـر الثفرة)، ج (2)، مطبوعات مجمع اللغة العربية بدمثق، 1996م، ص 14، 27، 43، 93، 178. " يتضــمن كتاب علم التعمية واســتخراج المُعمى عند العرب - بجزئيه الأول والثانى - تحقيقًا لأحد عثــر مخطوطًا تُعد من نفائس علم التعمية، وبتصـفح كلا الجزأين قد نم اسـتخراج بعض ضـــروب التعمية التى لها صلة قوية بأنواع فن التأريخ فى الأدب الديوانى. وقد جاء تعريف التعمية مختصرًا وجاء عرض بعض ضروبها

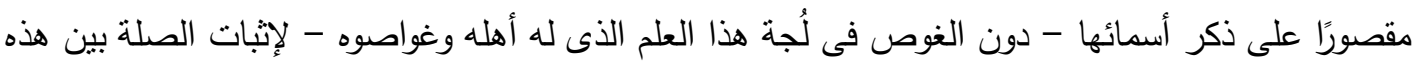
الضروب وبين الأنواع التى نظم بها الشعراء العثمانيون تواريخهم.

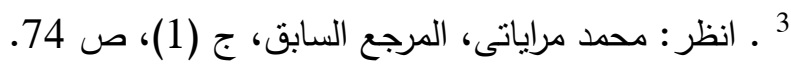

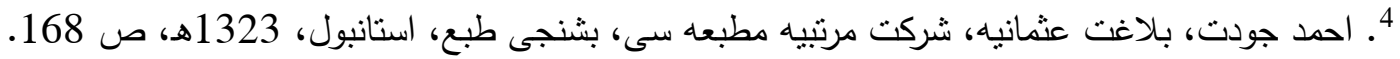
5. Rıdvan Canım, Klâsik Türk Edebiyatında Tarih Düşürme Sanatı ve Bir Ebced Ustası: Adanalı Sürûrî, Atatürk Üniversitesi Sosyal Bilimler Enstitüsü Dergisi, 2009, S: 105 .

$$
\text { 6. مصــطفى صـادق الرافعى، تاريخ آداب العرب، ج (3)، دار الكتب العلمية، ط (1)، بيروت، ، 2000، }
$$

8. إن أبجد هى أول الألفاظ الثمانية التى اعتاد العرب أن يدلوا بها على حروفهم لتذكرهم بها، وترتيب هذه

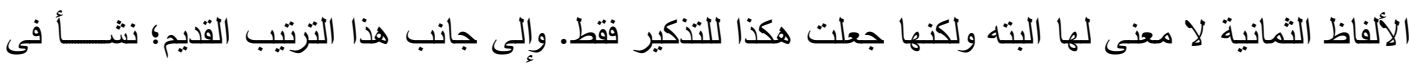
عصر متقدم الترتيب الآخر المستعمل الآن، ولقد انبعث هذا الترتيب من وضع الحروف المتشابهة فى الرسم،

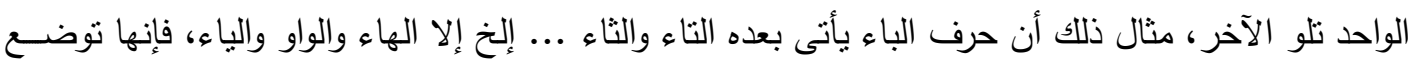
فى الآخر، وهو ( أ ، ب ، ت ، ث ، ج ، ح ، خ ل.... الخ ) ، كما يُلاحظ أن للاعتبارات الصــونية بعض الأثر فى هذا التزتيب. - انظر : موجز دائرة المعارف الإسلامية، المرجع السابق، ص 59 - 60. 
وقد أخذ العرب اصطلاح الدلالة بالأحرف على الأعداد قديمًا عن السريان، فإنهم كانوا يعبرون عن الأعداد بالحروف، كالعبرانيين واليونانيين، والحروف عند الســريانيين مرنبة ترتيب حروف (أبجد ...) غير أن العرب زادوا عليها كلمتي (تخذ وضظغ) وهي التي سموها الروادف، وأعدادها من . .0 إلى ... . . . - انظر : مصطفى صادق الرافعى ، المرجع السابق، ص صـ 294. كما أن هنالك ترتيبًا آخر للحروف الأبجدية قد جُمعت فى تسـع كلمات وضُـبطت على النحو التالى: ( ايقغ، بكر ، جلش، دمت، هنث، وسـخ، زعذ، حفض، طصـظ ) ، فمراتب هذه الكلمات قد رتبت على مراتب الأعداد

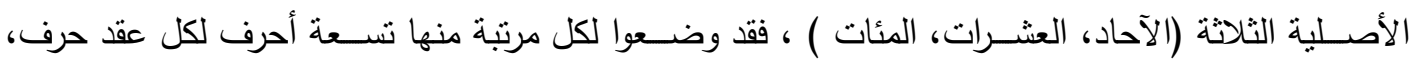
فالحرف الأول من كل كلمة من مرتبة الآحاد والثانى مرتبة العشـرات والثالث مرتبة المئات، والحرف الرابع من الكلمة الأولى من مرتبة الألوف، فالحرف الأول من الكلمة الأولى وهو الألف بواحد والثانى منها وهو الياء بعثــرة والثالث وهو القاف بمائة والرابع وهو الغين بألف، وعلى هذا الترتيب فيكون الحرف من الكلمة الأخيرة وهو الطاء بنسعة والثانى وهو الصاد بنسعين والثالث وهو الظاء بتسعمائه. - انظر : محمد بن محمد بن محمد (ســبط الماردينى)، رقايق الحقايق فى حهـــــاب الدرج والدقايق، مخطوط

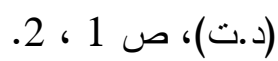

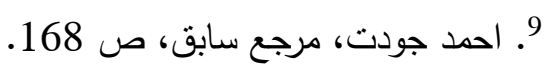
10. Tahir'ül-Mevlevî, Edebiyat Lüğatı, hzl. Kemal Edip Kürkçüoğlu, Enderun Kitabevi, İstanbul, 1973, S.38 - 39.

${ }^{11}$.Serhan Aıkan ispirli,Türk Edebiyatında Tarih Düşürme Geleneği, A. Ü. Türkiyat araştırmaları Enstitüsü Dergisi, Sayı 14, Ankara, 2000, S.80.

12. İskender Pala, Ansiklopedik Divan Şiiri Sözlüğü, L. M. yayınları, 12.bask1, İstanbul, 2003, S.451.

13 . احمد جودت، مرجع سابق، ص172.

${ }^{14}$. Tahir'ül-Mevlevî, a.g.e, S.146.

15. اسـمه الحقيقى سـيد عثمان، ومخلصــه " سـرورى" ، هو شـاعر ديواى اثــتهر بمهارته فى نظم التاريخ وتعميته، ولد فى آضـــهـ عام (1752م)، وتعلم اللغة العربيةواللغة الفارســية ودرس الأدب بها، وقد بدأ بنظم التاريخ عندما كان فى الحادية والعشرين من عمره، كان يستعمل " حزنى" كمخلص شعرى له فى قصائده ولكن قام بتغيره إلى "سرورى" بعد مجيئه إلى استانبول والتى عاش ونوفى بها عام عام (1814م). -BKZ: Atilla Batur, mad. Sürüri, İslâm Ansiklopedisi, C38, 2010, S.172.

16 . احمد جودت، مرجع سابق، ص 169 : ص 172. 
17 .كوبرلى زاده محمد فواد، شــــهاب الدين ســـليمان، معلومات ادبيه، برنجى جلد، قناعت مطبعه ســـى،

$$
\text { 18 استانبول، 1330هـ، ص308. }
$$

${ }^{19}$. Serhan A1kan ispirli, a.g.e, S.81.

$$
\text { 20 - احمد جودت، مرجع سابق، ص185، } 186 .
$$

21 . Tahir'ül-Mevlevî, a.g.e, S.39.

22 ـ محمد جلال، عثمانلى ادبياتى نمونه لرى، مطبعٌْ صفا وانور، استانبول، 1312ه، ص 230.

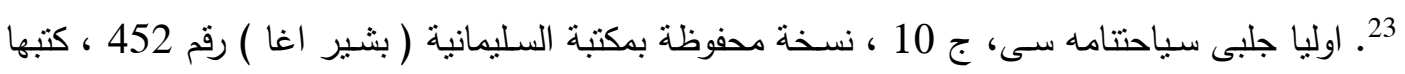
محمد حافظ القرآن المجيد من تلاميذ محمد راسم كاتب السراير العام، ص 206.

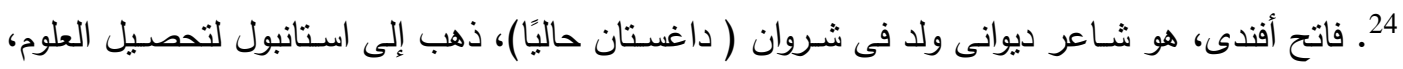

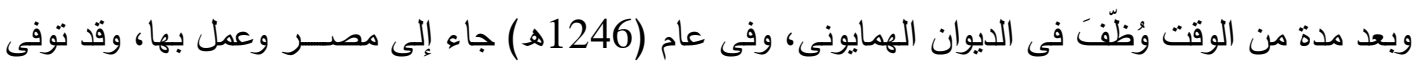
فيها عام (1250هـ).

- انظر : شمس الدين سامى، قاموس الأعلام، بشنجى جلد، مهران مطبعه سى، استانبول، 1314هـــ، ص

25 . Robert Mantran, Inscriptions turques ou de l'époque turque du Caire, IFAO, 1972, P. 219.

- محمود حامد الحسينى، الأسبلة العثمانبة بمدينة القاهرة، مكتبة ددبولى، د.ت، ص212.

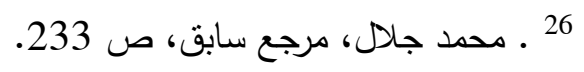

27. Tahir'ül-Mevlevî, a.g.e, S.148.

${ }^{28}$. a.e, S.148.

${ }^{29}$. Serhan A1kan ispirli, a.g.e, S.86.

${ }^{30}$. a.e, S.84.

${ }^{31}$. a.e, S.84.

32 ـ احمد جودت، بلاغت عثمانيه، ص 184.

- İskender Pala, a.g.e, S.452.

33 . Tahir'ül-Mevlevî, a.g.e, S.146: 147.

34 ـ دوتا: هى صفة فارسية مُركبة من العدد (دو= 2) ومن اللاحقة (تا) التى تلحق بالعدد للترقيم ولا تُضيف شىء لمعنى الرقم، فيقال: دوتا أى اثثين، ده تا أى عشرة ، هزار تا أى ألف، .. إلخ. - انظر : على اكبر دهخدا، لغتتامه دهخدا (بر اساس حروف الفبا)، جلد (5)، سازمان مديريت و برنامه بيزي كثور، 1341هـ، ص 415. 
35 ـ احمد جودت، مرجع سابق، ص 182 : ص 183.

${ }^{36}$. Serhan A1kan ispirli, a.g.e, S.86.

37 . a.e, S.85.

38 . a.e, S.88.

39 . a.e, S.88.

40 إن الأنواع التى اصطلح عليها العرب فى التأريخ الثعرى هى:

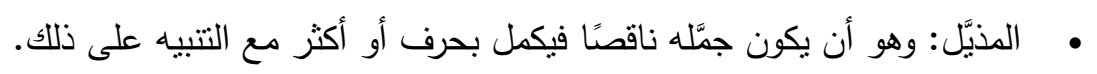

• المستوفى: وهو ما لا تحتاج كلماته ضميمة غيرها، كأكثر التواريخ المتداولة.

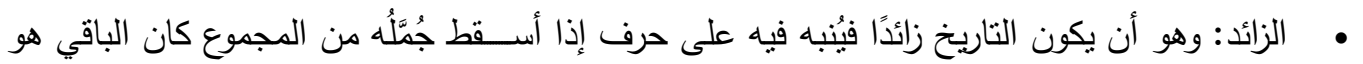

التاريخ.

• المنتوَج: وهو ما تحسب أوائل كلماته دون باقيها.

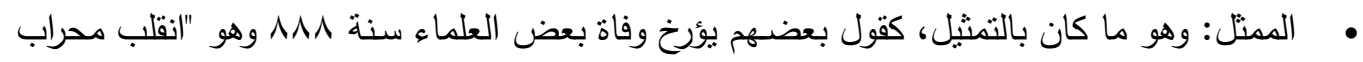
الديانة والدين والزهد" والمراد حروف الدال في هذه الكلمات، والدال كما لا يخفى ثُرسم هكذا (د) فإذا

انقلبت الدالات الثلاث، صارت هكذا (^^^) وهو عدد السنة المؤرخ بها. • المُهمل والمُعجم: وهو ما يُحسب فيه الحروف المهملةوالحروف المعجمة.

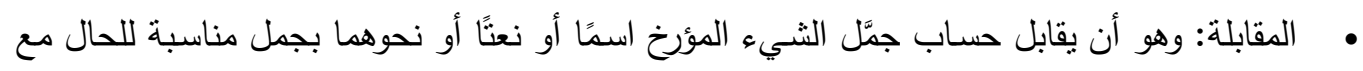

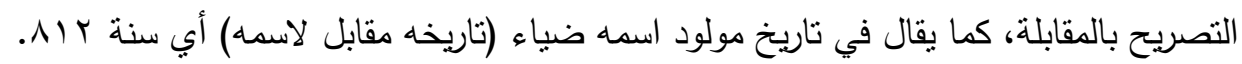

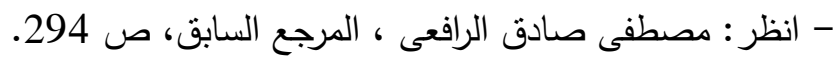

${ }^{41}$. Tahir'ül-Mevlevî, a.g.e, S.149. 


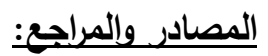

أولاً: المصادر والمراجع العربية:

1. محمد بن محمد بن محمد (ســبط الماردينى)، رقايق الحقايق فى حســاب الدرج والدقايق، مخطوط

2. موجز دائرة المعارف الإسلامية، مركز الثارقة للإبداع الفكرى، ج (1)، ط (1)، 1998م.

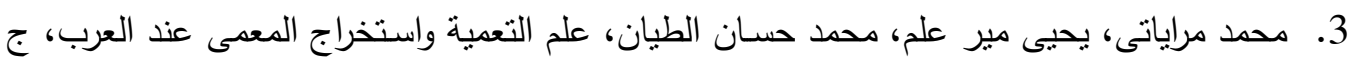

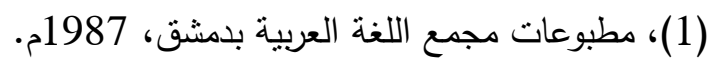

4. محمود حامد الحسينى، الأسبلة العثمانية بمدينة القاهرة، مكتبة مدبولى، (د.ت).

5. مصطفى صادق الرافعى، تاريخ آداب العرب، ج (3)، دار الكتب العلمية، ط (1)، بيروت، 2000.

ثانيًا: المصادر والمراجع العثمانية:

1. احمد جودت، بلاغت عثمانيه، شركت مرتبيه مطبعه سى، بشنجى طبع، استانبول، 1323هـ.

2. اوليا جلبى سياحتنامه سـى، ج 10 ، نسـخة محفوظة بمكتبة السليمانية ( بشـير اغا ) رقم 452 ،

كتبها محمد حافظ القرآن المجيد من تلاميذ محمد راسم كاتب السراير العام.

3. محمد جلال، عثمانلى ادبياتى نمونه لرى، مطبعهُ صفا وانور ، استانبول، 1312هـ.

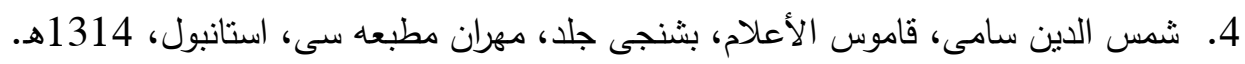

5. كوبرلى زاده محمد فواد، شـهاب الدين سـليمان، معلومات ادبيه، برنجى جلد، قناعت مطبعه سـى،

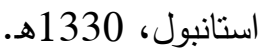

ثالثًا: المراجع التركية:

1. İskender Pala, Ansiklopedik Divan Şiiri Sözlüğü, L. M. yayınları, 12.baskı, İstanbul, 2003.

2. Rıdvan Canım, Klâsik Türk Edebiyatında Tarih Düşürme Sanatı ve Bir Ebced Ustası: Adanalı Sürûrî, Atatürk üniversitesi Sosyal Bilimler Enstitüsü Dergisi, 2009.

3. Serhan Aıkan ispirli,Türk Edebiyatında Tarih Düşürme Geleneği, A. Ü. Türkiyat araştırmaları Enstitüsü Dergisi, Sayı 14, Ankara, 2000. 
4. Tahir'ül-Mevlevî, Edebiyat Lüğatı, hzl. Kemal Edip Kürkçüoğlu, Enderun Kitabevi, İstanbul, 1973.

لإيعًا: المراجع الفرنسية:

1. Robert Mantran, Inscriptions turques ou de l'époque turque du Caire, IFAO, 1972.

خامسًا: القواميس القارسية:

على اكبر دهخدا، لغتتامه دهخدا (بر اســاس حروف الفبا)، جلد (5)، ســـازمان مديريت و برنامه ريزي كثور، 1341هـ. 